\title{
Baby Busts and Baby Booms: The Fertility Response to Shocks in Dynastic Models*
}

\author{
Larry E. Jones \\ University of Minnesota \& \\ Federal Reserve Bank of Minneapolis \\ lej@umn.edu
}

\author{
Alice Schoonbroodt \\ The University of Iowa \& \\ Centre for Population Change \\ alice-schoonbroodt@uiowa.edu
}

\section{July 12, 2016}

\begin{abstract}
While there has been a substantial effort to understand the Demographic Transition alongside the transition to sustained economic growth, fertility fluctuations have not been analyzed in the business cycle literature. This paper builds a model of fertility choice with dynastic altruism, age-structured population and aggregate productivity shocks. We show that, under reasonable parameter values, fertility is pro-cyclical and that, following a shock, fertility continues to cycle. Applied to the U.S. experience in the 20th century, the Great Depression generates a baby bust of $58 \%$ of that seen in the U.S. in the 1930 s, followed by a Baby Boom of $77 \%$ of that seen in the U.S. in the 1950s. As observed in U.S. estate data, the model predicts that small cohorts receive relatively large per child transfers from parents. Finally, statistical analysis across countries in the 1930s and 1950s further supports our theory.
\end{abstract}

Keywords: Fertility cycles, stochastic growth models, dynastic models. JEL Classification Numbers: J11, J13, E13, O11.

*The authors thank the National Science Foundation, Grant SES-0962432, and the ESRC Centre for Population Change for financial support. We also thank Robert Barro, Thomas Baudin, Michele Boldrin, Rui Castro, V.V. Chari, Simona Cociuba, Martin Gervais, Mikhail Golosov, Jeremy Greenwood, David Hacker, Grant Hillier, John Knowles, Christos Koulovatianos, Ellen McGrattan, Thomas Sargent, Henry Siu, Michèle Tertilt and Guillaume Vandenbroucke for helpful comments. 


\section{Introduction}

While economists have developed models of business cycles to understand fluctuations in macroeconomic variables at least since the seminal papers by Brock and Mirman (1972) and Kydland and Prescott (1982), the analysis of fertility fluctuations has been omitted from this research agenda. Similar to the attempt at understanding the Demographic Transition alongside the transition to sustained economic growth (for seminal papers, see Becker and Barro 1988 and Barro and Becker 1989), understanding fertility fluctuations alongside business cycles is important for similar reasons (see e.g., Lucas 2002). This paper therefore combines business cycle theory with the theory of fertility choice. We first derive theoretical results in a simple model. We then assess the quantitative importance of the mechanisms in a more comprehensive model, applied to the particularly dramatic fertility fluctuations in the U.S. over the course of the 20th century.

The fertility fluctuations in the U.S. during the 20th century can be summarized as follows. In the first part of the century, fertility rates continued a decrease that demographers associate with the Demographic Transition. This drop started in the mid 19th century: Total Fertility Rates (TFR) fell from 5.7 to 3.0 children per woman over the period from 1850 to 1925. In the years that followed, there was an even more abrupt drop during the years of the Great Depression from 3.0 to 2.1. Indeed, women in their prime fertility years during the Great Depression had, on average, only 2.2 children in their entire lifetime. These women, born between 1905 and 1915, had fewer children than any previous cohort. Following this, fertility rebounded significantly during the 1950s and early 1960s, the Baby Boom. At its peak, TFR reached 3.6, while Cohort Fertility (CFR) showed a similar, but smaller, increase up to 3.2. Only in the 1970s did fertility return to the levels seen in the 1930s.

To analyze this event as well as fertility fluctuations more generally, we build a model of fertility choice à la Barro-Becker with aggregate productivity shocks. In addition to the stochastic component, the model extends existing Barro-Becker type models to include multiple periods of productive life.

In a simple version of the model, we assume that labor is the only factor of production. Here, we show that fertility is procyclical provided that there is sufficient curvature in the period utility function, or that the goods costs of children are large enough, relative to time costs. In addition, the policy function for current fertility as a function of past fertility is negatively sloped around the steady state. We find that the dynamics of adjustment following a movement off a balanced growth path is one of dampened oscillations. Putting these two effects together, a large negative income shock is met 
with a contemporaneous reduction in fertility, followed by a Baby Boom a generation later. Thus, the Great Depression (or any other similarly large negative income shock) would trigger a baby bust, followed by a Baby Boom a generation later.

These basic mechanisms are best understood as variants of standard effects of growth models - namely, the desire to smooth consumption - and of models à la Barro-Becker, where the number and well-being of children are non-separable in the utility of the parent. To gain some intuition about the mechanism, note that in Barro-Becker type models, parents care about their own consumption stream and a composite good including the number of children and their expected lifetime utility. While fertility is chosen today, the only way to affect children's utility is through a transfer chosen in the future that affects the children's choice of consumption and fertility. Now, suppose the current shock is lower than average. Then, to equalize the marginal utility of own consumption today and expected marginal utility from the composite good, the parent decreases fertility today. In the future, the parent compensates for low fertility by giving higher transfers to each child, which increases fertility of the next generation above its steady state value. We then proceed to show that low intertemporal elasticity of substitution and more than one period of productive life are essential for our mechanism.

The simple model highlights the main mechanisms. To assess their quantitative importance, however, we add several relevant features. First, we allow for alternative investments (besides children), namely, physical and human capital. While physical capital is homogeneous, human capital is embodied in people and therefore age-specific, just like labor. Depending on parameter values, the presence of alternative investments may curb or exacerbate the fertility response to the contemporaneous shock. After a period of low fertility due to a negative shock, dampened oscillations follow for similar reasons as before. Second, since the size of transfers depends on the relative income across cohorts, we allow for exogenous productivity growth. Third, we also introduce a period of retirement to allow for reasonable life lengths and savings motives.

We use a calibrated version of this model to simulate the size of the contemporaneous and delayed response of fertility to productivity shocks. After calibrating to U.S. averages between 1991 to 2010, we find that the contemporaneous response to a 1 percent deviation in productivity is about 1.1 percent, while the elasticity one period later is -0.8. This implies that the response of (completed) fertility to a 'standard recession' (say, productivity is 5 percent below trend for 2 years) is relatively small - of the order of 0.025 children per woman with a subsequent Baby Boom of slightly smaller size.

Realistically, it seems unlikely that fertility decisions are affected by quarter to quarter fluctuations in productivity (as addressed in the business cycle literature). Rather, a 
prolonged boom or bust is required to prompt large fertility effects. Indeed, we find that the reduction in fertility implied by the model as a response to the 13 percent decrease in productivity during the Great Depression is 58 percent of the observed pre-WWII baby bust in Total Fertility Rates (TFR). Moreover, the subsequent endogenous fluctuations in fertility triggered by this bust, in conjunction with the productivity boom in the 1950s and 1960s, captures about 77 percent of the post-WWII Baby Boom in TFR.

One testable implication of the mechanism is that small cohorts should get larger per child transfers from their parents. Data on private intergenerational transfers for this time period are hard to come by. Though imperfect, we use estate data from Piketty and Saez (2001, 2003) and find that, as predicted by the theory, the small cohort born in the 1930s received much larger transfers per recipient than did the large cohort born in the $1950 \mathrm{~s}$.

Many other demographers and economists have studied the Baby Boom, but they have focused on different channels. First, some have put forth the idea that the Baby Boom was a consequence of low fertility during the Great Depression - i.e., the Baby Boom was 'catching up.' However, completed fertility (CFR) was low for both the women immediately preceding and immediately following the Baby Boom and hence, this cannot be true at the level of the individual mother. It can, in principle, hold across cohorts in a dynastic model. This distinction is relevant in our analysis and is one of our motivations for studying a dynastic model. In a similar context, catching up at the individual level appears to be important in response to wars. For example, Vandenbroucke (2014) analyzes the effect of WWI on income and fertility in France. He finds catching up at the individual, rather than dynastic level.

Second, one of the key hypotheses put forward by economic demographers for these large and opposite swings in fertility is known as the 'Easterlin hypothesis,' see Easterlin (1961, 1968, 1978, 1987). In a nutshell, the idea behind this hypothesis is that fertility was exceptionally low during the Great Depression because of the large negative shock to incomes, emphasizing differences between expected lifetime income relative to "material aspirations formed in childhood.' Then, due in substantial part to the fact that fertility had been so low during the 1930s, the Baby Boom occurred. The mechanism through which low fertility leads to high fertility one generation later has usually been attributed to feedback effects of the resulting unbalanced age-structure on the relative wages of young fertile workers to those of older workers. This operates in combination with differences in expected lifetime income relative to "material aspirations formed in childhood.' For the most part, Easterlin's work remains descriptive. ${ }^{1}$ Some formaliza-

\footnotetext{
${ }^{1}$ The so-called 'Easterlin hypothesis' has developed over Easterlin's own work and has been inter-
} 
tions of parts of his description are worth mentioning, however. First, Feichtinger and Dockner (1990) assume a positive relationship between births and the difference between actual and expected consumption in a choice-theoretic framework. In addition, many authors have assumed that the relationship between fertility today and past fertility has a negative slope. Based on this assumption, they analyzed the resulting dynamics of age-structured populations, see Lee (1974) and Samuelson (1976) for early analyses of this kind. ${ }^{2}$ Finally, Lee (2008) suggests that Easterlin's feedback effect can be generated by using a CES production specification, in which different age groups are not perfect substitutes. The mechanisms driving our results are considerably different than those emphasized by Easterlin and the authors mentioned above. Our mechanisms are mainly based on consumption smoothing motives. For example, we assume that effective labor supplied by different ages of workers are perfect substitutes in production. Nevertheless, fertility cycles are generated through the curvature of and non-separability in preferences. Hence, we provide a choice-theoretic foundation for the negative slope in the relationship between fertility today and past fertility and, hence, the cycles.

Furthermore, some authors have also used choice-theoretic dynamic macroeconomic models to study the Baby Boom in the 1950s and 1960s. Three key examples of these alternative theories are Greenwood et al. (2005), Albanesi and Olivetti (2014) and Doepke et al. (2015). In Greenwood et al. (2005), the highlighted channel pertains to the effects of the drastic improvement in technologies of home production during the post-WWII period. In essence, these improvements temporarily made having children cheaper, generating the boom. Albanesi and Olivetti (2014) emphasize the decrease in maternal mortality as a cause of the Baby Boom. This decrease in mortality also increased the incentive to invest in human capital, triggering the return to low fertility in the 1970s. In Doepke et al. (2015), the authors emphasize the relatively high female participation rate that took place during WWII. Because of learning on the job, this experience made that specific cohort of women relatively high productivity. Because of this, the cohort of women entering their twenties in the 1950s faced a relatively tough job market, causing them to delay entering the workforce and have larger than normal families. Thus, the primary channels emphasized in those papers differ from ours. It should be noted that, in principle, these models can lead to oscillations as well (although those papers are not focused on that issue). For instance, in an earlier version, Greenwood et al. (2002)

preted in various ways by other authors. For an excellent overview until 1998, see Macunovich (1998). She 'focuses just on the fertility aspects of the Easterlin hypothesis,' which is our focus as well. For a more general overview, see Macunovich and Easterlin (2008).

${ }^{2}$ Feichtinger and Sorger (1989) extend Samuelson's initial model to continuous time. 
also discuss cycles, echo effects and fertility waves but find that their (non-dynastic) model converges quickly to the steady state (see VIII. Supplement - B). Albanesi (2012) points out that reductions in maternal mortality lead to opposite movements in fertility for subsequent cohorts of women. Similarly, in Doepke et al. (2015), the initial shock leads to dampened cycles (the cohort after the Baby Boom mothers has low fertility again, because low labor supply by the Baby Boom mothers once again makes working attractive). In contrast to these papers, our approach is also able to capture the sizable downward movement - relative to trend - in fertility as seen in the 1930s.

There is also a large statistical literature on the cyclicality of fertility. Sobotka et al. (2011) review this literature extensively and analyze several major recessions in detail. We provide additional statistical evidence. Since both the Great Depression and the Baby Boom are phenomena that occurred in many different countries, it should be true that countries that had deeper Depressions in the 1930s also had larger baby busts in the 1930s. Moreover, those with larger baby busts should have experienced larger Baby Booms in the 1950s. In Section 6, we show that this relationship is indeed present, conditional on the economic circumstances in the 1950s. These observations further support our theory. We also provide evidence on the recent recession across U.S. states and find that states with a larger drop in income per capita tend to have a larger reduction in fertility in 2008. Whether this drop will have permanent effects on completed fertility triggering further dampened oscillations, remains to be seen. ${ }^{3}$

Finally, our findings can rationalize the observations in Butz and Ward (1979) as follows. In brief, they find that fertility, while procyclical, has become less responsive to business cycle frequency fluctuations over time. In our model, this finding can emerge for two reasons. First, the size of the effects that we find are smaller when the costs of children are in terms of time. Since there has been a large increase in labor force participation among married women, the opportunity cost of time to raise children has become increasingly important. Second, the fertility response to productivity shocks is mitigated due to continuing fluctuations triggered by the Great Depression. In our data analysis, we show that, controlling for past productivity shocks is crucial in finding a positive correlation between fertility and current shocks.

In Section 2, we review the data for the U.S. since 1900 in detail, focusing on both the size and timing of movements in fertility and productivity. The main mechanism is laid out in Section 3 and analytic results are presented. We present the quantitative model in Section 4. In Section 5, we explore the quantitative implications of a calibrated

\footnotetext{
${ }^{3}$ See Online Appendix O.4 for details.
} 
version of the model compared to U.S. data. Finally, we present statistical evidence in Section 6. Section 7 concludes.

\section{Twentieth century U.S. data}

In this section, we lay out the basic facts about the time paths of productivity and fertility in the U.S. over the 20th century. We begin with the facts pertaining to the growth in productivity using a consistent measure for total factor productivity (TFP) and labor productivity (LP) from Chari et al. (2007) extended to 2010. As most economists know, this period is one of more or less continued growth in productivity with a few interruptions. The most significant of these is the Great Depression. Figure 1 shows the natural logarithms of TFP and LP over the period from 1901 to 2010.

The facts about productivity over this period can be described as follows:

1. the continual upward trend;

2. the marked decline below trend that took place in the 1930s and early 1940s;

3. the return to trend in the early 1950s;

4. the significant increase above trend that took place in the 1950s and 1960s;

5. the productivity slowdown since the 1970s.

This timing of the movements of productivity around trend fits well with the movements in fertility seen in the data. Figure 2 shows the time path of the Total Fertility Rate (TFR) and Cohort Total Fertility Rates (CFR) (by birth year of mother plus 25 years) over the period from 1850 to 2010. We have two time series for TFR, which calculates how many children a woman would have over her lifetime if current age-specific fertility rates were to prevail in the future. The first series is the one prepared by Haines (1994) using Census data and hence is available only every 10 years. The second TFR series comes from the Natality Statistics Analysis from the National Center for Health Statistics. It is available at annual frequencies, but only since 1917. The CFR series comes from Jones and Tertilt (2008) and counts how many children were born to a particular cohort of women at the end of their fertile period. Implicitly, it is equivalent to adding age-specific fertility rates pertaining to a particular cohort of women over time. Its frequency is five-year birth cohorts.

Initially, fertility is still in the midst of what is known to demographers as the Demographic Transition, the marked fall in fertility (and mortality) that has occurred in all developed countries. This fall accelerates from the late 1920s to the mid 1930s. Fertility then increases to reach its peak in the Baby Boom of the 1950s and 1960s. It appears that a good description would be: 
Figure 1: Total Factor Productivity (TFP) and Labor Productivity (LP), 1901-2010 $(1929=100)$

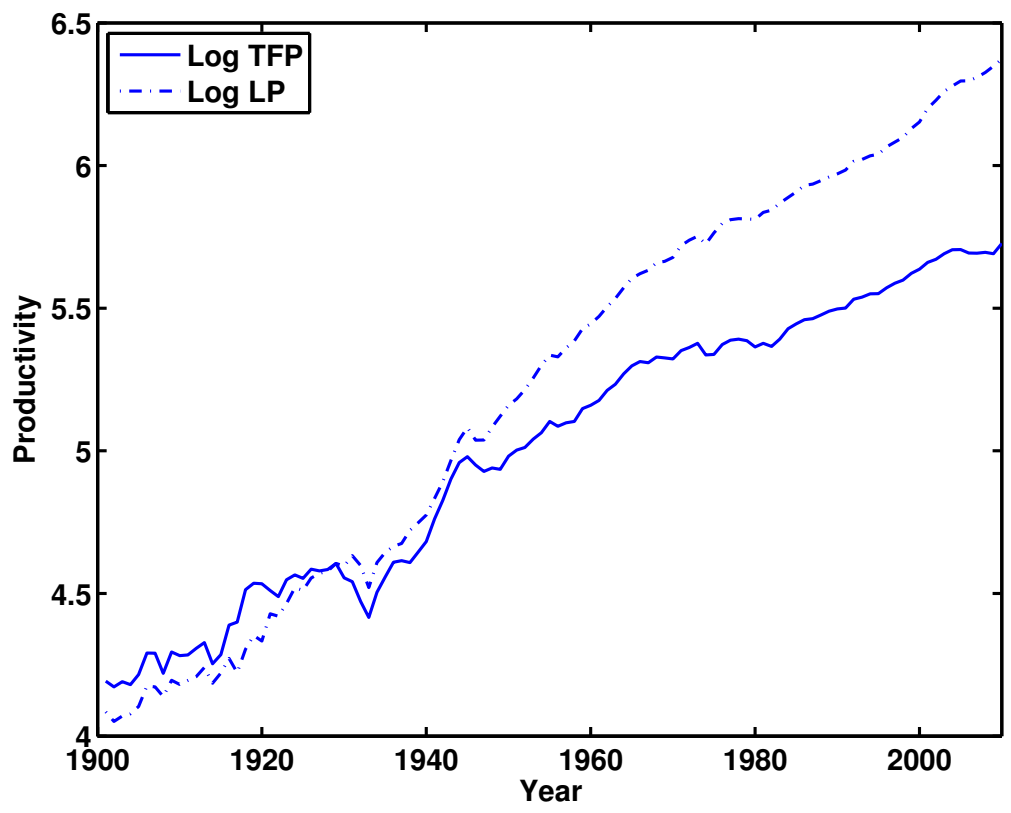

1. high, and fairly constantly decreasing fertility from 1850 until 1925, when it reaches a TFR of about 3.0 children per woman; ${ }^{4}$

2. an acceleration of the rate at which fertility is falling between 1925 and 1933 (from $\mathrm{TFR}=3.0$ to $\mathrm{TFR}=2.1$ );

3. constant, but low, fertility over the period from 1933 to 1940, with the level at about $\mathrm{TFR}=2.2$;

4. rapidly rising fertility from 1940 to 1957, with TFR going from 2.2 up to 3.7;

5. high, stable fertility from 1957 to 1961 at about $\mathrm{TFR}=3.6$;

6. a rapid decrease from 1961 to 1976, with TFR going from 3.6 down to 1.7;

7. a slight increase and then stable low fertility over the remainder of the period, with the level at about $\mathrm{TFR}=2 .{ }^{5}$

${ }^{4}$ Since the data on TFR are only available decade by decade and since it covers the U.S. as a whole, it is not apparent in this figure that there was a significant drop in births in the South during and after the Civil War. See Hacker (1999), who estimates annual data on Crude Birth Rates (CBR) for this period for the South compared to the North.

${ }^{5}$ The fertility drop from 2008 to now is visible at the very end of the figure. We discuss the most recent recession in more detail in Online Appendix O.4. 
Figure 2: Cohort Fertility Rate (CFR) and Total Fertility Rate (TFR), 1850-2010

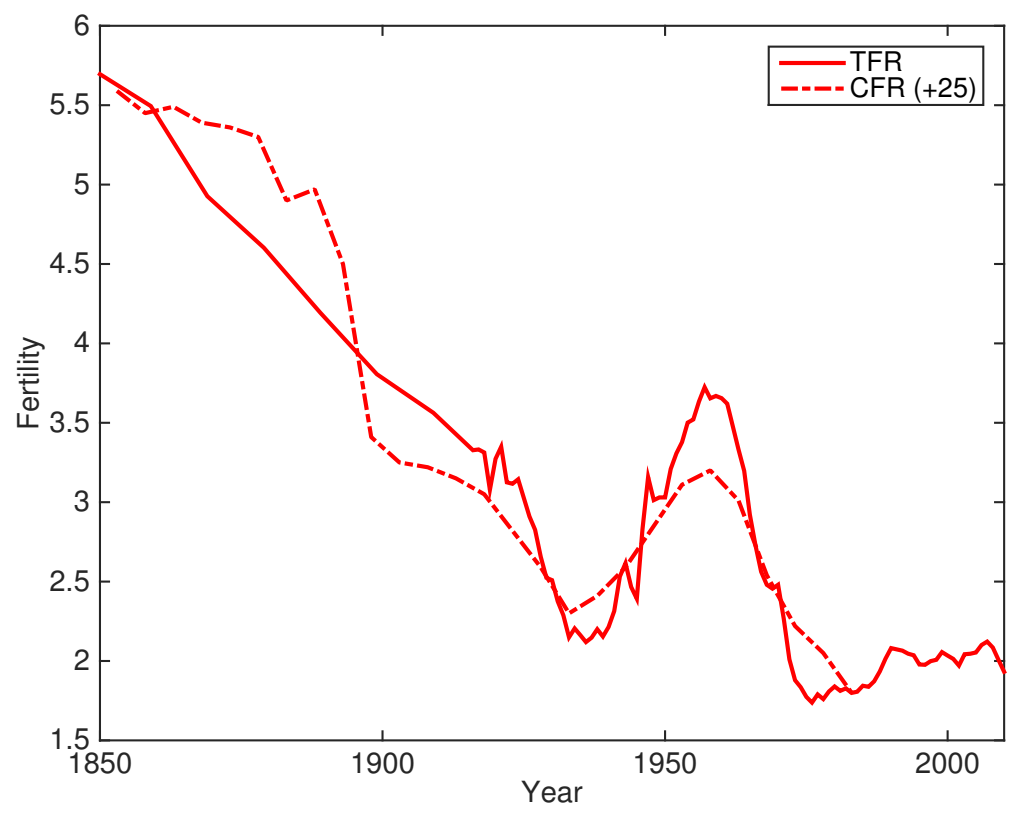

We will refer to 2 and 3 as the pre-WWII baby bust, 4 and 5 as the post-WWII Baby Boom and 6 as the baby bust of the 1970s. The exact sizes of these features of the data depend on how one treats the trend growth in productivity and trend decrease in fertility over the period. For example, was there a common, exogenous growth rate in productivity over the entire period with higher-frequency (albeit highly autocorrelated) fluctuations around this trend? Or, were there several regimes of growth? For fertility, one can see that while TFR decreases smoothly over time, the early CFR data shows that the largest decrease occurred for cohorts of women born between 1858 (4.9 children per women) and 1878 (3.25 children per woman). The fluctuations thereafter, however, look quite similar in both series, though somewhat larger in TFR than CFR.

To address fluctuations, we fit a linear trend to the (ln) TFP and LP series from 1901 to 2000 ( $\ln P_{t}=\alpha_{0}+\alpha_{1} t+\epsilon_{t}$, where $\left.P=\{T F P, L P\}\right)$, and detrend TFR using an HP filter (smoothing parameter, $w=20,000$ ). We obtain annual percent deviations over this period; these are plotted in Figure 3. Several alternative detrending methods were studied with very similar results.

Although it is not perfect, there is an impressive coincidence in timing. The coefficient of correlation between annual TFP and TFR deviations for the years 1901 to 2000 is 0.4 , with a coefficient of 0.7 from 1901 to 1940 and 0.2 from 1941 to 2000. This 
Figure 3: Total Fertility Rate (TFR), Total Factor Productivity (TFP) and Labor Productivity (LP) Percent Deviations From Trend, 1901-2010

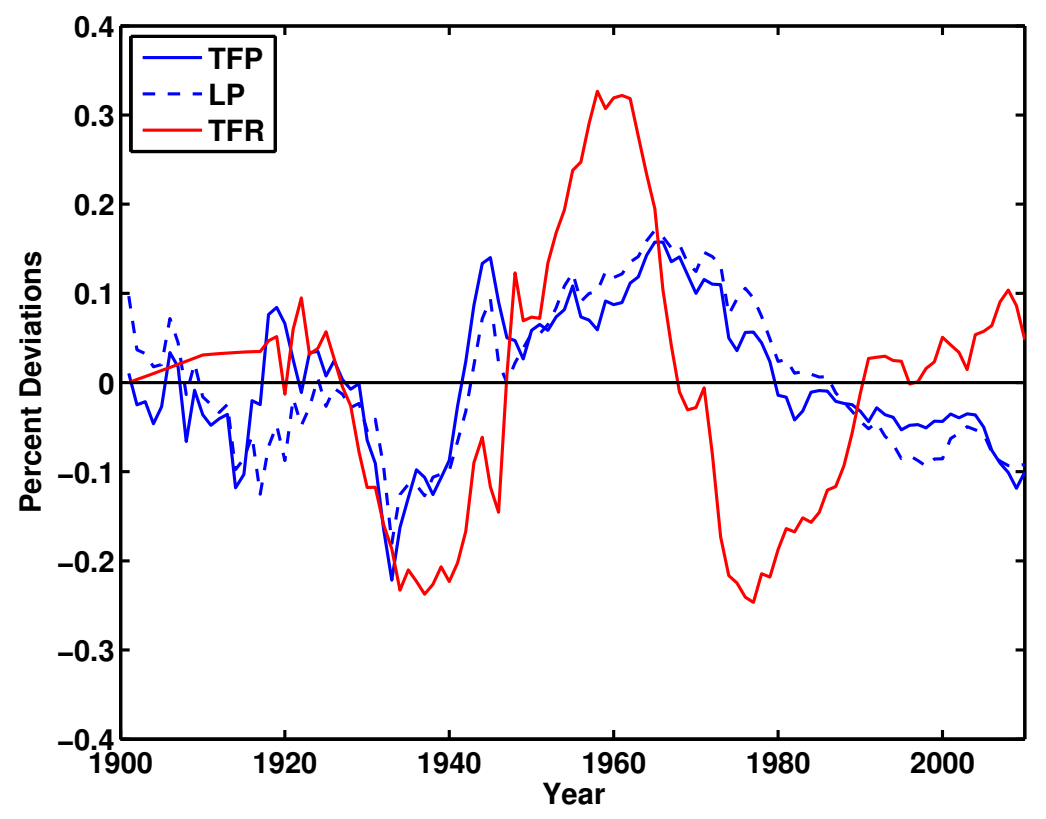

suggests that the U.S. TFR is procyclical during the early time period, with a much weaker correlation prevailing thereafter (see also Butz and Ward, 1979). As suggested by the model below, one reason for the decrease in the correlation may be the increase in female labor supply, which made the opportunity cost of children - women's wagesprocyclical.

What our model simulation also captures is the large downward deviation in the 1930s due to the large negative shock during the Great Depression and a Baby Boom following endogenously as a response to the baby bust itself, one generation later. We therefore also run the following regression. Let $\widehat{X}_{t}$ denote the percent deviation from trend in variable $X$ in period $t$.

$$
\widehat{T F R}_{t}=\lambda_{0}+\lambda_{1} \widehat{P}_{t}+\lambda_{2} \widehat{P}_{t-l}+\varepsilon_{t},
$$

where $P=\{T F P, L P\}$ and $l \in\{20, \ldots, 25\}$. The results for $l=20$ are given in Table 1 . Similar results are evident for larger values of $l$.

These regressions show that the coefficients on contemporaneous productivity $\left(\lambda_{1}\right)$ are positive and significantly different from zero, while the coefficients on productivity a generation ago $\left(\lambda_{2}\right)$ are negative and significantly different from zero, $\lambda_{1}$ and $\lambda_{2}$ are of similar magnitude in absolute value and the constant $\left(\lambda_{0}\right)$ is likely to be zero. 
Table 1: U.S. TFR and Productivity: Regression results

\begin{tabular}{l|l||l|l}
\hline \hline Indep. Var. & Coefficient & Indep. Var. & Coefficient \\
\hline Constant & -0.0027 & Constant & -0.0019 \\
$\widehat{T F P}_{t}$ & $0.8292^{* *}$ & $\widehat{L P}_{t}$ & $0.6722^{*}$ \\
$\widehat{T F P}_{t-20}$ & $-0.8432^{* *}$ & $\widehat{L P}_{t-20}$ & $-0.6664^{*}$ \\
\hline \hline
\end{tabular}

*, **: Significantly different from zero at $5 \%$ and $1 \%$, respectively.

\section{The main mechanism}

In this section, we lay out a simple model of the response of fertility to period-by-period stochastic movements in productivity. To do this, we use a model of fertility based on that developed in Becker and Barro (1988) and Barro and Becker (1989)(Barro-Becker henceforth). The simplification that we make is to assume that there is no physical (or human) capital in the model. Thus, the flow of income is due solely to labor income. On the other hand, we add a stochastic component as well as an additional period of work and consumption to the basic Barro-Becker model. In Section 4, we include physical and human capital, exogenous productivity growth and a period of retirement, but the basic mechanism described here remains.

\subsection{Setup}

Demographics: Every person lives for three periods, one as a child and two as an adult. Children (age $a=0$ ) do nothing. At age $a=1$, young workers consume, save, have children and supply one unit of labor (net of time spent to raise children) to earn a wage, $w_{t}^{1}$. At age $a=2$, old workers consume, earn interest $R_{t+1}$ on their savings, supply one unit of labor inelastically to earn a wage, $w_{t+1}^{2}$, make transfers to their (adult) children, $t_{t+1}^{1}$, but are no longer fertile.

Preferences: Adults care about consumption, the number of children and their children's future utility. Following the original Barro-Becker formulation, we assume that the utility of a person who was born in period $t-1$ and whose first period as an adult is in period $t$ is given by:

$$
U_{t}^{1}=u\left(c_{t}^{1}\right)+\beta E_{t}\left[u\left(c_{t+1}^{2}\right)+g\left(n_{t}\right) U_{t+1}^{1}\right]
$$

where $c_{t}^{a}$ is consumption at age $a$ in period $t, n_{t}$ is the number of children that the 
household has and $U_{t+1}^{1}$ is the utility that their typical child will receive. ${ }^{6}$

Assuming $g(n)=n^{\eta}$ and $u(c)=\frac{c^{1-\sigma}}{1-\sigma}$, following Jones and Schoonbroodt (2010b), there are two sets of parameter restrictions satisfying the natural monotonicity and concavity restrictions of $U_{t}^{1}$ : [AI.] $0<1-\sigma \leq \eta<1$ or [AII.] $0>1-\sigma \geq \eta{ }^{7}$

Under AI., $g$ is increasing and utility is positive, while under AII. $g$ is decreasing but utility is negative, so that, in both cases, parent's utility is increasing in the number of children. Furthermore, under AI., the desire to smooth consumption over time and across generations is low, while under AII., it is high. These distinctions are relevant for the results below. We often concentrate on the case where $\eta=1-\sigma$, allowed under both configurations. There are at least two advantages to this choice. First, simplification occurs because the direct utility benefit of increasing population as well as the indirect utility cost (of diluting per capita consumption) exactly cancel out in this case. Second, changing the side of the parameter space (AI. versus AII.) also involves changing $\eta$ relative to $1-\sigma$, except in the case where $\eta=1-\sigma$. When comparing the two sides of the parameter space, this assumption allows for only an absolute change without the relative change.

Shocks: In each period, we assume that there is an aggregate shock, $s_{t}$, which causes the entire age-specific wage profile to shift up and down. Thus, in period $t$, wages are given by $\left(w_{t}^{1}, w_{t}^{2}\right)=\left(s_{t} w^{1}, s_{t} w^{2}\right)$, where $w^{1}$ and $w^{2}$ are parameters. We assume that the $s_{t}$ are $i . i . d . .^{8}$

Timing of Choices: Within each period, we will use a particular timing for the choices made by the young and old workers. The timing we use is:

(i) the aggregate shock for the period, $s_{t}$, is chosen by nature;

(ii) old workers choose how to divide their labor, $w_{t}^{2}\left(s_{t}\right)$, and interest income between own consumption, $c_{t}^{2}$, and transfers per child, $t_{t}^{1}$;

(iii) young workers make their choices of consumption, savings and fertility given both their own wages, $w_{t}^{1}\left(s_{t}\right)$ and the transfers they received from their parents.

This timing is convenient because it follows that the resulting (sub-game perfect) equilibrium choices that are made coincide with the solution to a Planner's problem. ${ }^{9}$

\footnotetext{
${ }^{6}$ In the quantitative model, we distinguish between time preference as measured by the discount factor, $\beta$ and the degree of altruism between generations within a period, $\phi$.

${ }^{7}$ The knife-edge case where $\sigma \rightarrow 1$ and $\eta=\delta(1-\sigma)$ can also be analyzed. See Jones and Schoonbroodt (2010b) or Schoonbroodt and Tertilt (2014) for details.

${ }^{8}$ In the quantitative model, we allow for exogenous productivity growth so that $\left(w^{1}, w^{2}\right)$ grow.

${ }^{9}$ Equivalence with the Planner's problem is shown in the proof of Proposition 1 in Online Appendix O.1. In general in Barro-Becker models with multiple periods of life, the equilibrium will only
} 
Budget constraints: We assume that the cost of children born in period $t$ is in terms of period $t$ consumption, but allow this cost to depend on the wage of young workers $\theta_{t}\left(w_{t}^{1}\right)$. This allows for the two most common ways of modeling child costs: goods costs $-\theta_{t}\left(w_{t}^{1}\right)=\theta_{t}$ - and time costs $-\theta_{t}\left(w_{t}^{1}\right)=b w_{t}^{1}$. Age $a=1$ adults save $x_{t+1}$ and earn a return, $R_{t+1}$, on these savings at age $a=2$. Finally, age $a=2$ parents make transfers, $t_{t+1}^{1}$, to each of their age $a=1$ children. Note that, due to curvature in utility and the absence of heterogeneity across children, the parent always wants to give the same transfer to each child. Also note that we do not restrict these transfers to be positive. ${ }^{10}$ The budget constraints for generation $t$ are given by:

$$
\begin{aligned}
& c_{t}^{1}+\theta_{t}\left(s_{t}\right) n_{t}+x_{t+1}=w_{t}^{1}\left(s_{t}\right)+t_{t}^{1} \\
& c_{t+1}^{2}+n_{t} t_{t+1}^{1}=w_{t+1}^{2}\left(s_{t+1}\right)+R_{t+1} x_{t+1} .
\end{aligned}
$$

Household problem: Taking the transfer from their own parents, $t_{t}^{1}$, and the behavior of descendants as given, generation $t$ chooses $c_{t}^{1}, c_{t+1}^{2}, n_{t}$ and $t_{t+1}^{1}$ to solve the following two problems in recursive form.

Young adults (of age $a=1$ ) solve:

$$
\begin{aligned}
& \qquad U^{1}\left(t^{1} ; s\right)=\max _{c^{1}, n^{\prime}, x^{\prime}}\left(u\left(c^{1}\right)+\beta E\left[U^{2}\left(n^{\prime}, x^{\prime} ; s^{\prime}\right)\right]\right) \\
& \text { subject to } \quad c^{1}+\theta(s) n^{\prime}+x^{\prime}=w^{1}(s)+t^{1} .
\end{aligned}
$$

Old adults (of age $a=2$ ) solve:

$$
U^{2}(n, x ; s)=\max _{c^{2}, t^{1^{\prime}}}\left(u\left(c^{2}\right)+g\left(n_{t}\right) U^{1}\left(t^{1^{\prime}} ; s\right)\right)
$$

subject to $\quad c^{2}+t^{1^{\prime}} n=w^{2}(s)+R x$.

Note that, since both $n$ and $t^{1^{\prime}}$ are choice variables, the overall household problem is not convex as written. In Online Appendix O.1, we follow Alvarez (1999) in performing a change of variables to dynasty aggregates to circumvent this problem.

coincide with the solution to a Planner's problem when the oldest individuals alive make all the choices within a period. This is because the altruism in the model is assumed to be in one direction only (from parents to children). However, since parents and children agree about how a child should divide his/her income between consumption and children, it is sufficient to have the older workers choose a transfer to the children.

${ }^{10}$ In the calibrated model below, transfers are always positive and hence, such a constraint would not bind. See Schoonbroodt and Tertilt (2014) for an analysis of transfer constraints in a similar context. 
Market Clearing: Goods and credit market clearing per old worker requires:

$$
\begin{aligned}
& n_{t-1} c_{t}^{1}+c_{t}^{2}+\theta_{t}\left(s_{t}\right) n_{t} n_{t-1}=n_{t-1} w_{t}^{1}\left(s_{t}\right)+w_{t}^{2}\left(s_{t}\right) \\
& n_{t-1} x_{t+1}=0 .
\end{aligned}
$$

\subsection{Procyclical fertility and endogenous oscillations}

In this section, we study the properties of the solution to the household problem outlined above. In particular, we examine how fertility choices today depend on both the current shock and past fertility. There are two qualitatively important properties that we want to highlight here. These are: i) fertility is procyclical and ii) fertility today depends negatively on fertility in the last period. The first depends, to some degree, on the details of the model - specifically, the parameters of utility and child costs. The second is a result relying on Barro-Becker models with multiple periods of productive life.

Assuming $\eta=1-\sigma$ and using the envelope condition, the first-order conditions for fertility and transfers, in per capita terms, can be written as:

$$
\begin{aligned}
\left(c_{t}^{1}\right)^{-\sigma} \theta_{t}\left(s_{t}\right) & =\beta E_{t}\left[\left(n_{t}\right)^{-\sigma} U_{t+1}^{1}-\left(c_{t+1}^{2}\right)^{-\sigma} t_{t+1}^{1}\right] \\
c_{t+1}^{2} & =n_{t} c_{t+1}^{1} .
\end{aligned}
$$

Next, use the first order condition for transfers in the goods market clearing condition to eliminate $c_{t}^{2}=n_{t-1} c_{t}^{1}$ and get

$$
c_{t}^{1}=w_{t}^{1}\left(s_{t}\right)+\frac{w_{t}^{2}\left(s_{t}\right)}{n_{t-1}}-\theta_{t}\left(s_{t}\right) n_{t} .
$$

Substituting this into the first-order condition for fertility, we get:

$$
\begin{aligned}
\operatorname{LHS}\left(n_{t}\right) & \equiv\left[s_{t} w^{1}+\frac{s_{t} w^{2}}{n_{t-1}}-\theta_{t}\left(s_{t}\right) n_{t}\right]\left[\theta_{t}\left(s_{t}\right)\right]^{-1 / \sigma} \\
& =\beta^{-1 / \sigma} n_{t}\left(E_{t}\left[U_{t+1}^{1}-\left(c_{t+1}^{1}\right)^{-\sigma} t_{t+1}^{1}\right]\right)^{-1 / \sigma} \equiv \operatorname{RHS}\left(n_{t}\right) .
\end{aligned}
$$

To gain some intuition, we first analyze this equation holding transfers, $t_{t+1}^{1}$, consumption, $c_{t+1}^{1}$, and children's utility, $U_{t+1}^{1}$, fixed. Figure 4 plots the different cases. The $R H S$ is an increasing function of $n_{t}$ and $R H S(0)=0$ (solid line), while the $L H S$ is a decreasing function of $n_{t}$ and $L H S(0)>0$ (solid line with x marker). Hence, for each value of $\left(s_{t}, n_{t-1}\right)$, there is a unique solution, $n_{t}=n\left(s_{t}, n_{t-1}\right)$.

In the goods cost case, $\theta_{t}\left(s_{t}\right)=\theta_{t}$, the intercept of the $L H S$ shifts up when $s_{t}$ goes 
Figure 4: The Fertility Response to a Positive Productivity Shock or Low Past Fertility

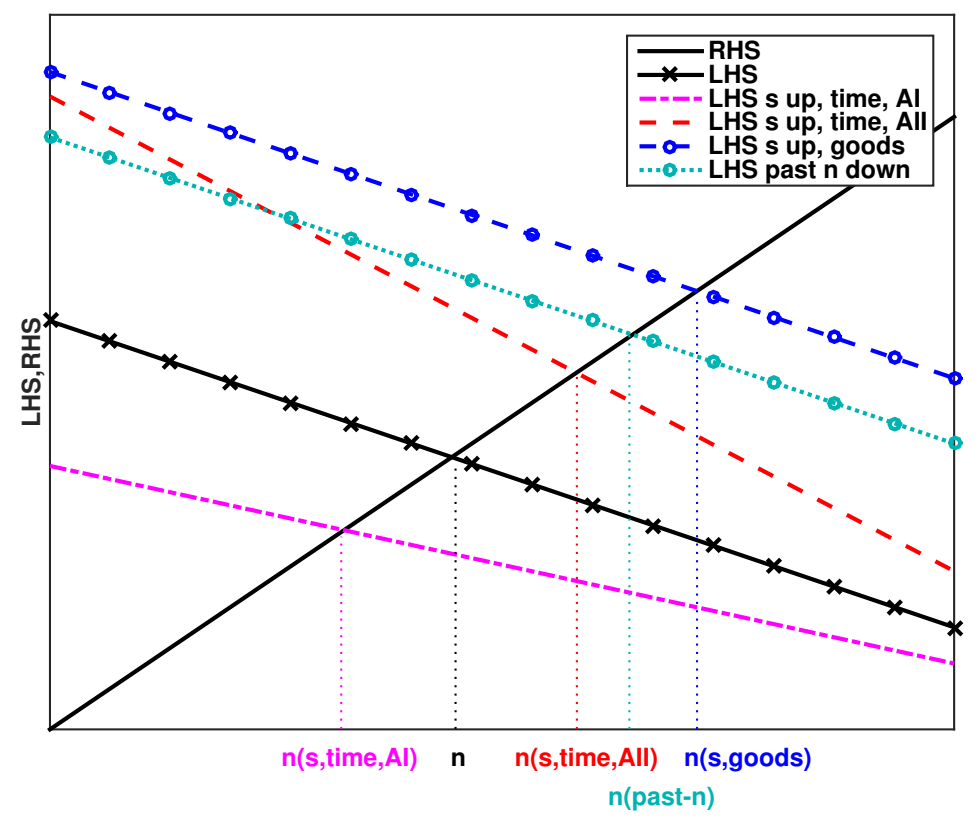

up - increasing fertility (dashed, circled line). Thus, fertility is procyclical in this case. When children cost time, $\theta_{t}\left(s_{t}\right)=b s_{t} w^{1}$, the $L H S$ depends on $s_{t}^{\frac{\sigma-1}{\sigma}}$. Hence, if $\sigma>1$, the LHS shifts up when $s_{t}$ goes up - increasing fertility (dashed line), but if $\sigma<1$, the $L H S$ shifts down when $s_{t}$ goes up - decreasing fertility (dotted line). The reason for this is that, in the time cost case, the opportunity cost of having children is itself procyclical. That is, income and substitution effects on fertility go in opposite directions. Which one dominates depends on whether we are in the high [AI.] or low [AII.] intertemporal elasticity case. Hence, fertility is procyclical in all cases, except if children cost only time and [AI.] holds.

In the equation above, we can also see that a decrease in past fertility, $n_{t-1}$, shifts the LHS up (dotted, circled line). This increases current fertility and gives rise to dampened oscillations. Notice, however, that this effect is only present if $w^{2}>0$-i.e., multiple periods of productive life are required.

These two effects illustrate the basic mechanism. ${ }^{11}$ A large negative productivity

\footnotetext{
${ }^{11}$ We have also derived results for the case where $\eta \neq 1-\sigma$. Although the equations are more complicated, the basic effects highlighted here remain. They are, however, slightly mitigated or exacerbated by additional, second-order effects. In particular, cyclical elasticities are exacerbated under [AI.] $(\eta>1-\sigma)$ and diminished under [AII.] $(\eta<1-\sigma)$ as compared to $\eta=1-\sigma$. To the contrary, dampened oscillations are diminished under [AI.] $(\eta>1-\sigma)$ and exacerbated under [AII.] $(\eta<1-\sigma)$ as compared to $\eta=1-\sigma$.
} 
shock (such as the Great Depression) causes a contemporaneous drop in fertility - a Baby Bust. This is the first effect discussed above. This drop is followed, a generation later, by above trend fertility due to the second effect, dampened oscillations - a Baby Boom. ${ }^{12}$

So far, we have held transfers, $t_{t+1}^{1}$, consumption, $c_{t+1}^{1}$, and children's utility, $U_{t+1}^{1}$, fixed in equation (4). Of course, through the choice of transfers from parents to children, these variables change as well. Whether these changes shift the RHS in or out and, hence, weakens or strengthens the effect on current fertility, $n_{t}$, depends on parameters. To see the effect on future fertility, $n_{t+1}$, note that parents care about their own consumption stream and a composite good made of the number of children and their expected lifetime utility, i.e., $g\left(n_{t}\right) E_{t}\left[U_{t+1}^{1}\right]$. While fertility, $n_{t}$, is chosen directly by the parent in period $t$, the only way for the parent to affect children's utility is through the per child transfer, $t_{t+1}^{1}$, chosen in $t+1$. This transfer affects the children's choice of consumption, $c_{t+a}^{a}$, and fertility, $n_{t+1}$. Because consumption and children are normal goods, increased transfers increase both consumption and fertility.

Now, suppose the current shock is low $\left(s_{t}<E\left(s_{t}\right)\right)$ and costs are mainly in terms of goods. Then, to equalize the marginal utility of own consumption today, $c_{t}^{1}$, and expected marginal utility from the composite good, the parent decreases fertility, $n_{t}$, today, thereby keeping up own current consumption, $c_{t}^{1}$. Children's utility, $U_{t+1}^{1}$, is expected to be relatively high in the future. There are two sources for this. To isolate the first effect, suppose people are only productive for one period $\left(w^{2}=0\right)$. Then, because shocks are i.i.d., the expected future shock is higher than the current shock, $E_{t}\left(s_{t+1}\right)>s_{t}$, and fertility would be expected to return to steady state in the future with $E_{t}\left(n_{t+1}\right)>n_{t}$. To generate a Baby Boom over and above steady state fertility, suppose people are productive for more than one period $\left(w^{2}>0\right)$. Then the wage of the parent, positively related to the shock, $E_{t}\left(w_{t+1}^{2}\right)=E_{t}\left(s_{t+1}\right) w^{2}$, is also expected to be relatively high in the future. Because of this, the parent plans on compensating for low fertility in the composite by giving higher transfers per child in the future. These higher transfers translate into both higher consumption and fertility for the next generation. Hence, in a model with more than one period of productive life, we generate procyclical fertility and dampened oscillations thereafter. ${ }^{13}$

\footnotetext{
${ }^{12}$ Note that it is important for the mechanism that the shocks are aggregate and not idiosyncratic. Since this is an endowment economy, savings are zero in equilibrium. A negative aggregate shock makes everyone want to save less or borrow more so that the interest rate, $R$, adjusts such that savings are zero again in equilibrium. In the quantitative model with physical capital in Section 4, equilibrium savings decrease in response to a negative aggregate shock for standard consumption smoothing purposes. We explore the quantitative implications in Section 5.

${ }^{13}$ Note that this last property holds even without shocks to productivity. For example, dampened
} 
Finally, we can use equation (6), the budget constraint at age $a=1$ and the fact that savings, $x_{t+1}$, are zero in equilibrium, to solve for transfers:

$$
t_{t}^{1}=\frac{1}{\phi^{1 / \sigma}+1}\left[\phi^{1 / \sigma} \frac{s_{t} w_{t}^{2}}{n_{t-1}}+\theta\left(s_{t}\right) n_{t}-s_{t} w^{1}\right] .
$$

Provided that $w_{t}^{2}>0, n_{t}$ is decreasing in $n_{t-1}$. Transfers, $t_{t}^{1}$, are therefore decreasing in past fertility, $n_{t-1}$, as well. Hence, one testable implication of the mechanism (which we also discuss in Section 5) is that smaller cohorts should get larger transfers per child from their parents.

We summarize these results in the following proposition. A formal proof can be found in Online Appendix O.1.

Proposition 1 Assume $\eta=1-\sigma$. Then:

A. current fertility, $n^{\prime}(s, n)$, is

a. procyclical if $\theta(s)=\theta$, or if $\theta\left(w^{1}\right)=b s w^{1}$ and $\sigma>1$;

b. countercyclical if $\theta(s)=b s w^{1}$ and $\sigma<1$;

B. both, current fertility, $n^{\prime}(s, n)$, and transfers, $t^{1}(s, n)$, are

a. independent of last period's fertility, $n$, if $w^{2}=0$;

b. decreasing in last period's fertility, $n$, if $w^{2}>0$.

Thus, if $w^{2}>0$ the model generates endogenous fertility cycles, triggered by productivity shocks and small cohorts tend to get larger transfers.

\section{The quantitative model}

In the previous section, we examined the main mechanism in a simple version of the model. To assess its quantitative importance, we add several relevant features. After setting up the model, we derive and discuss equilibrium conditions. We then describe the solution algorithm. The next section calibrates the model and simulates the equilibrium path.

oscillations could be triggered by an unexpected change in a fundamental parameter where deterministic dampened oscillations would occur in the transition to the new steady state/balanced growth path. This property is also not an artifact of having exactly two periods of productive life. See an earlier version of this, Jones and Schoonbroodt (NBER 2010, Section 5.4), for a discussion of the case of three periods productive life. 


\subsection{Model Setup}

In this section, we set up the quantitative model, highlighting additions to the simple model. First, we allow for alternative investments (besides children), namely, physical and human capital. Where physical capital is homogeneous, human capital is embodied in people and therefore age-specific, just like labor. Second, we allow for exogenous productivity growth. Exogenous productivity growth impacts the relative earnings of subsequent cohorts. It therefore affects intergenerational transfers - an important variable for the main mechanism. Finally, we add a period of retirement to get reasonable life-lengths and savings motives. ${ }^{14}$

\subsubsection{Demographics}

A period is 20 years. Every person lives for four periods, one as a child and three as an adult. There is an initial age distribution of the population given by $\left(N_{0}^{3}, N_{0}^{2}, N_{0}^{1}\right)$, where $N_{0}^{3}$ is the number of initial old (i.e., their age in period $t=0$ is $a=3$ ). We normalize by assuming that $N_{0}^{3}=1$.

Children (age $a=0$ ) do nothing. At age $a=1$, young workers consume, have children, invest in their children's human capital, freely borrow or save at interest rate $R_{t+1}$, receive a transfer $t_{t}^{1}$ from their age 2 parents and supply one unit of labor net of time spent to raise and educate children. This earns a wage per unit of labor, $w_{t}^{1}$, which is a function of their own human capital, $h_{t}$. At age $a=2$, old workers consume, freely borrow or save at interest rate $R_{t+2}$, receive a transfer $t_{t+1}^{2}$ from their retired parents, make a transfer $t_{t+1}^{1}$ to their age 1 children and supply one unit of labor inelastically to earn a wage, $w_{t+1}^{2}$. This, again, is a function of their own human capital, $h_{t}$. Note that they are no longer fertile. In the last period of their lives, age $a=3$, agents are retired, make a transfer to their children, consume the rest of their savings, but are no longer productive, $w_{t+2}^{3}=0$.

Let $N_{t}^{a}$ be the number of people of age $a$ in period $t$. Let $n_{t}$ be the number of births per young adult in period $t$. Then, the laws of motion for population are given by:

\footnotetext{
${ }^{14}$ We have also extended this model to analyze the effects of decreased mortality, increased productivity growth and the introduction of social security on trends and fluctuations in fertility. The main results of this paper go through with these additions. Observed changes in mortality and productivity growth not only affect fertility levels in steady state (see Jones and Schoonbroodt, IER 2010, for a detailed analysis) but also generate dampened oscillations along the transition path. That is, an unanticipated change in these parameters induces a transition to a new balanced growth path with a different age-structure and oscillations are a feature of the transition path. Generally speaking, the main reason for fertility fluctuations remains productivity shocks since changes in mortality and productivity growth tend to generate fluctuations in opposite directions, thereby canceling each other out. The introduction of Social Security increases the level of transfers from parents to children with little effect on fertility. Details are available upon request.
} 


$$
\begin{aligned}
& N_{t+1}^{1}=n_{t} N_{t}^{1} \\
& N_{t+1}^{a+1}=N_{t}^{a} \text { for } a=1,2 ; \\
& N_{t}^{a}=0 \text { for } a>3 .
\end{aligned}
$$

\subsubsection{Production}

We assume that physical capital and effective labor are the two factors of production. The production function, $Y_{t}=F_{t}\left(K_{t}, L_{t}\right)=s_{t} F\left(K_{t}, \gamma^{t} L_{t}\right)$, is strictly increasing, concave and homogeneous of degree 1 in $(K, L), \gamma$ is the rate of growth of effective labor productivity and effective labor is $L_{t}=L_{t}^{1}+L_{t}^{2}$, where $L^{1}$ is age 1 effective labor and $L^{2}$ is age 2 effective labor. We specify how effective labor is produced at the household level in the next subsection. The rental rate of capital will be denoted $r_{t}$ and the wage rate per unit of effective labor is $w_{t}$. Physical capital depreciates at rate $\delta \in[0,1]$.

We assume productivity shocks, $s_{t}$, are $i . i . d$ over time with $E\left(s_{t}\right)=1$ and $\operatorname{Var}\left(s_{t}\right)=$ $\sigma_{s}^{2}$. For readability, we omit $s_{t}$ as an argument of prices and quantities whenever possible.

\subsubsection{Preferences}

Adults care about consumption, the number of children and their children's future utility. Following the original Barro-Becker formulation, we assume that the utility of a person who was born in period $t-1$ and whose first period as an adult is in period $t$ is given by:

$$
U_{t}^{1}=V_{t}^{1}+\phi \beta g\left(n_{t}\right) E_{t} U_{t+1}^{1},
$$

where $U_{t}^{1}$ represents the full value of utility of an age $a=1$ adult in period $t$ looking from that point forward, $V_{t}^{1}$ is the expected utility this person gets from his own path of consumption, $n_{t}$ is the number of children and $U_{t+1}^{1}$ is the utility that his typical child will receive.

Let $c_{t}^{a}$ be the amount of consumption for the typical age $a$ person in period $t$. We assume that utility from the time path of own consumption $\left(\left(c_{t}^{1}, c_{t+1}^{2}, c_{t+2}^{3}\right)-\right.$ young worker, old worker, retirement) is of the form:

$$
V_{t}^{1}=E_{t} \sum_{a=1}^{3} \beta^{a-1} u\left(c_{t+a-1}^{a}\right) .
$$

We distinguish between time preference as measured by the discount factor, $\beta$, and the degree of altruism between generations within a period, $\phi$. That is, $\phi=1$ means that a person cares as much about the utility of his children as he cares about his own (see Manuelli and Seshadri, 2009). 
As in the previous section, the functions $g$ and $u$ are of the form $g(n)=n^{\eta}$ and $u(c)=\frac{c^{1-\sigma}}{1-\sigma}$. Parameters are restricted to either [AI.] $0<1-\sigma \leq \eta<1$ or [AII.] $0>1-\sigma \geq \eta$. Also, to ensure that utility is bounded, we assume that the effective discount factor is less than one, i.e., $\phi \beta \gamma^{1-\sigma}<1$. Finally, as before, we make the simplifying assumption that $\eta=1-\sigma$.

\subsubsection{Budget constraints}

Human capital, effective labor and the wage rate: Generation $t$ entering adulthood as young workers have the human capital that their parents provided them with in the previous period, $h_{t-1}$. This human capital is productive for the next two periods of generation $t$ 's life. Effective labor is a concave function of human capital, and is linear in labor hours. That is, $h_{t-1}$ units of human capital combined with $x$ units of labor translates into $A^{a} h_{t-1}^{\psi} x$ units of effective labor at age $a$. Hence, the wage per unit of labor is $w_{t+a-1}^{a}\left(h_{t-1}\right)=A^{a} h_{t-1}^{\psi} w_{t+a-1}$. That is, it is equal to the amount of effective labor per unit of labor times the wage per unit of effective labor.

Costs of children: We assume that the cost of children born in period $t$ is partly in terms of consumption goods, $\theta_{t}$, and partly in terms of time of young workers, a fraction $b$ per child. The time constraint is $0 \leq b n_{t} \leq 1$. Human capital costs $\nu_{t}$ goods and $\zeta$ units of time. To ensure the existence of a balanced growth path, we assume that goods costs of children, $\theta_{t}$, and human capital, $\nu_{t}$, grow at the rate of labor augmenting technological progress, $\theta_{t}=\gamma^{t} \theta$ and $\nu_{t}=\gamma^{t} \nu$.

Private transfers: At age 1 and 2, agents receive a transfer, $t_{t+a-1}^{a}, a=1$, 2, from their parents. At age 2 and 3, they decide on a per-child transfer $t_{t+a}^{a}, a=1,2$ themselves. As in the previous section, we assume that the timing is such that parental transfers occur after $s_{t+2}$ has been observed but before children make their decisions .

Budget constraints: Given this, the budget constraints for generation $t$ are given by:

$$
\begin{aligned}
& c_{t}^{1}+\left(\theta_{t}+\nu_{t} h_{t}\right) n_{t}+x_{t+1}^{1}=w_{t}^{1}\left(h_{t-1}\right)\left(1-n_{t}\left(b+\zeta h_{t}\right)\right)+t_{t}^{1} ; \\
& c_{t+1}^{2}+x_{t+2}^{2}+n_{t} t_{t+1}^{1}=w_{t+1}^{2}\left(h_{t-1}\right)+R_{t+1} x_{t+1}^{1}+t_{t+1}^{2} ; \\
& c_{t+2}^{3}+n_{t} t_{t+2}^{2}=R_{t+2} x_{t+2}^{2},
\end{aligned}
$$

where $x_{t+a}^{a}$ are savings at age $a$ made in period $t$ and $R_{t}$ is the rate of return to savings between periods $t$ and $t+1$.

Now, it can be shown that because agents can freely borrow and lend, the timing of transfers does not matter for choices other than that of savings. This means that only the present value of transfers is determined in this model. Given that we need a transfer 
after the productivity shock $s_{t+2}$ is realized, we set $t_{t}^{1}=0$ without loss of generality.

\subsubsection{Market clearing}

Let $X_{t}$ be aggregate investment. Goods, capital and labor market clearing requires

$$
\begin{aligned}
& \sum_{a=1}^{3} N_{t}^{a} c_{t}^{a}+X_{t}+\left(\theta_{t}+\nu_{t} h_{t}\right) N_{t+1}^{1}=s_{t} F\left(K_{t}^{d}, \gamma^{t} L_{t}^{d}\right) \\
& N_{t-1}^{1} x_{t}^{1}+N_{t-1}^{2} x_{t}^{2}=K_{t}^{d} \\
& L_{t}^{1}+L_{t}^{2}=L_{t}^{d}
\end{aligned}
$$

where

$$
\begin{aligned}
& L_{t}^{1}=A^{1} h_{t-1}^{\psi} N_{t}^{1}\left(1-\left(b+\zeta h_{t}\right) n_{t}\right) ; \\
& L_{t}^{2}=A^{2} h_{t-2}^{\psi} N_{t}^{2} .
\end{aligned}
$$

\subsection{Equilibrium conditions}

Since productivity grows at rate $\gamma$, all per capita variables grow at this rate with the exception of the number of children and human capital per child. ${ }^{15}$ We therefore work with detrended variables, dividing all relevant variables by $\gamma^{t}$. The effective discount factor is then given by $\phi \beta \gamma^{1-\sigma}$, which we assume to be less than one so that utility is bounded.

\subsubsection{Firm's optimality conditions}

The representative firm who takes the rental rate of capital and the wage rate per unit of effective labor as given, maximizes profits by setting marginal products equal to prices:

$$
\begin{aligned}
& r_{t}=F_{K}\left(K_{t}^{d}, \gamma^{t} L_{t}^{d}\right) \\
& w_{t}=\gamma^{t} F_{L}\left(K_{t}^{d}, \gamma^{t} L_{t}^{d}\right) .
\end{aligned}
$$

We assume a Cobb-Douglas production function where $\alpha$ is the share of capital in output. Because $F$ is constant returns to scale, the firm's optimality conditions can be written in per old worker terms (using labor market clearing after detrending):

$$
\begin{aligned}
& r_{t}=s_{t} k_{t}^{\alpha-1}\left(\left[A^{1} h_{t-1}^{\psi} n_{t-1}\left(1-\left(b+\zeta h_{t}\right) n_{t}\right)+A^{2} h_{t-2}^{\psi}\right]\right)^{1-\alpha} \\
& w_{t}=s_{t} k_{t}^{\alpha}\left(A^{1} h_{t-1}^{\psi} n_{t-1}\left(1-\left(b+\zeta h_{t}\right) n_{t}\right)+A^{2} h_{t-2}^{\psi}\right)^{-\alpha} .
\end{aligned}
$$

\footnotetext{
${ }^{15}$ The reason why the number of children and human capital per child do not grow is because both goods and time costs (the latter through wages) grow, instead.
} 
where $k_{t}$ is the detrended capital stock per old worker and $w_{t}$ is the detrended wage per unit of effective labor.

\subsubsection{Household's optimality condition}

The household in generation $t$ (born in $t-1)$ chooses $c_{t}^{1}\left(s_{t}\right), x_{t+1}^{1}\left(s_{t}\right), h_{t}\left(s_{t}\right), n_{t}\left(s_{t}\right)$, $c_{t+1}^{2}\left(s_{t+1}\right), x_{t+2}^{2}\left(s_{t+1}\right), c_{t+1}^{3}\left(s_{t+2}\right)$ and $t_{t+2}^{2}\left(s_{t+2}\right)$ to maximize utility in equation (10) subject to the constraints in equations (12), taking as given the parental transfer $t_{t+1}^{2}\left(s_{t+1}\right)$ and the behavior of children. Since $n_{t}, h_{t}$ and $t_{t+2}^{2}$ are all choice variables but are multiplied in the parent's budget constraints, the constraints in equations (12) are not convex as written. With a simple change in variables following Alvarez (1999), however, we can write an equivalent problem with a convex constrained set. After taking first-order conditions, we switch back to the original variables, albeit detrended. The first-order conditions for the household can then be summarized as: ${ }^{16}$

$$
\begin{aligned}
& x_{t+1}^{1}: \quad\left(c_{t}^{1}\right)^{-\sigma}=E_{t}\left[R_{t+1} \beta\left(\gamma c_{t+1}^{2}\right)^{-\sigma}\right] \\
& x_{t+2}^{2}:\left(c_{t+1}^{2}\right)^{-\sigma}=E_{t+1}\left[R_{t+2} \beta\left(\gamma c_{t+2}^{3}\right)^{-\sigma}\right] \\
& t_{t+2}^{2}:\left(c_{t+2}^{3}\right)^{-\sigma}=\phi\left(n_{t} c_{t+2}^{2}\right)^{-\sigma} \\
& h_{t}: \quad\left(c_{t}^{1}\right)^{-\sigma}\left(\nu+\zeta w_{t}^{1}\left(h_{t-1}\right)\right) \\
& =E_{t}\left[\phi\left(\beta \gamma^{1-\sigma}\right)\left(n_{t} c_{t+1}^{1}\right)^{-\sigma} A^{1} h_{t}^{\psi-1} w_{t+1} \psi\left(1-\left[b+\zeta h_{t+1}\right] n_{t+1}\right)\right. \\
& \left.+\phi\left(\beta \gamma^{1-\sigma}\right)^{2}\left(n_{t} c_{t+2}^{2}\right)^{-\sigma} A^{2} h_{t}^{\psi-1} w_{t+2} \psi\right] \\
& n_{t}: \quad\left(c_{t}^{1}\right)^{-\sigma}\left(\theta+b w_{t}^{1}\left(h_{t-1}\right)\right) \\
& =E_{t}\left[\phi\left(\beta \gamma^{1-\sigma}\right)\left(n_{t} c_{t+1}^{1}\right)^{-\sigma} A^{1} h_{t}^{\psi} w_{t+1}\left(1-\psi\left(1-\left[b+\zeta h_{t+1}\right] n_{t+1}\right)\right)\right. \\
& \left.+\phi\left(\beta \gamma^{1-\sigma}\right)^{2}\left(n_{t} c_{t+2}^{2}\right)^{-\sigma} A^{2} h_{t}^{\psi} w_{t+2}(1-\psi)\right]
\end{aligned}
$$

together with the budget constraints in equations (12) which, in detrended variables, can be simplified to:

$$
\begin{aligned}
& c_{t}^{1}+\left(\theta+\nu h_{t}\right) n_{t}+\gamma x_{t+1}^{1}=w_{t}^{1}\left(h_{t-1}\right)\left(1-n_{t}\left(b+\zeta h_{t}\right)\right) \\
& c_{t+1}^{2}+\gamma x_{t+2}^{2}=w_{t+1}^{2}\left(h_{t-1}\right)+R_{t+1} x_{t+1}^{1}+t_{t+1}^{2} \\
& c_{t+2}^{3}+n_{t} t_{t+2}^{2}=R_{t+2} x_{t+2}^{2} .
\end{aligned}
$$

The first two equations in (16) are standard Euler equations, equalizing marginal utility of consumption today and expected marginal utility next period multiplied by the return to savings. The third equation equalizes the marginal utility from consumption of age $a=3$ parents and the marginal utility from consumption of their age $a=2$ children

\footnotetext{
${ }^{16}$ Details can be found in Online Appendix O.2.
} 
(from the parent's point of view). Note that the first three equations together imply that $n_{t-1} n_{t-2} c_{t}^{1}=n_{t-2} c_{t}^{2} \phi^{1 / \sigma}=c_{t}^{3} \phi^{2 / \sigma}$. That is, within a period, total consumption of different age groups, are weighted by $\phi^{(a-1) / \sigma}$. When $\phi=1$ total consumption of different age groups are equalized.

The last two equations in (16) equalize the marginal cost to the marginal benefit of either one more unit of human capital (holding the number of children constant), or one more child (holding human capital per child constant). The marginal costs in terms of forgone consumption of the age $a=1$ parent is standard. The marginal benefit of one more unit of human capital is the marginal return to human capital for the child over its working lifetime. This is evaluated in terms of the child's consumption, $c_{t+a}^{a}$, and seen from the parent's point of view, $\phi$. The marginal benefit of an extra child to the parent is the extra wage it brings to the dynasty. Again, this is evaluated in terms of the child's consumption, $c_{t+a}^{a}$, and seen from the parent's point of view, $\phi$. These marginal benefits are more easily understood if we disregard time costs for a moment, setting $b=0$ and $\zeta=0$. In this case, we see that the two types of benefits are almost symmetric: the marginal benefit of additional human capital is weighted by the share of human capital in the production of effective labor, $\psi$, while the marginal benefit of an extra child is weighted by its complement, $(1-\psi)$. To see where these weights come from, note that total effective labor produced by the parents is $n_{t} h_{t}^{\psi}=n_{t}^{1-\psi} H_{t}^{\psi}$ where $H_{t}=h_{t} n_{t}$ is total human capital produced by the parent. Hence, the share of human capital is $\psi$, while the share of labor is $(1-\psi)$. With positive time costs, $b>0$ and $\zeta>0$, at age $a=1$ the children spend time with their own children. Form the parent's point of view, payoffs to the number and quality of children are therefore reduced in this case.

Unlike in the simple model, equilibrium savings and investments in human capital decrease in response to a negative aggregate shock for standard consumption smoothing purposes. This generates additional incentives to adjust fertility. On the one hand, in order to smooth consumption, the parent need not decrease fertility to the same extent because she can also decrease savings or human capital per child. On the other hand, lower savings and lower human capital translate into lower wages for the children. Taken together, these effects may encourage or discourage fertility adjustments today. Which of these effects dominates depends on parameter values. In Section 5.3, we describe these quantitative effects in detail.

\subsubsection{Law of motion, market clearing and no-arbitrage condition}

The law of motion for the aggregate capital stock, $K_{t}$, is: 


$$
K_{t+1}=(1-\delta) K_{t}+X_{t}
$$

Using this, goods market clearing in detrended variables per old worker becomes $n_{t} c_{t}^{1}+c_{t}^{2}+\frac{c_{t}^{3}}{n_{t-2}}+n_{t-1} k_{t+1}-(1-\delta) k_{t}+\left(\theta+\nu h_{t}\right) n_{t} n_{t-1}=s_{t}\left(k_{t}^{\alpha}\left(A^{1} h_{t-1}^{\psi} n_{t-1}\left(1-\left(b+\zeta h_{t}\right) n_{t}\right)+A^{2} h_{t-2}^{\psi}\right)^{1-\alpha}\right.$

while credit market clearing in detrended variables per old worker is given by

$$
n_{t-2} x_{t}^{1}+x_{t}^{2}=n_{t-2} k_{t-1}
$$

In addition, we need a no-arbitrage condition so that households are indifferent between saving and investing in capital directly. That is:

$$
R_{t}=r_{t}+1-\delta
$$

\subsection{Computing the equilibrium}

Using the resource constraint in equation (18)[1], first-order conditions for the firm in equation (15)[2] and those for the household in equation (16)[5], we solve for a steady state of eight variables: $r, w, n, c^{1}, c^{2}, c^{3}, h$ and $k$. We use a sixth-order approximation of log-variables in Dynare++ (see Kamenik, 2011). ${ }^{17}$ After computing the steady state for the eight variables above, we solve for steady state transfers and savings from the budget constraints in (17) and credit market clearing in (19) outside of Dynare++. ${ }^{18}$ Impulse responses and historical simulations are performed around the stochastic steady state using the same equations as for the steady state.

\section{Quantitative results}

In this section, we use the facts about the time paths of productivity and fertility in the U.S. to perform quantitative experiments on the model. To do this, we calibrate parameters to selected moments of the data. We then use this model to explore two kinds of experiments. First, we compute the elasticity of fertility with respect to a productivity

\footnotetext{
${ }^{17}$ To show that the approximation is quite good, we compute approximation errors following a similar strategy as Caldara et al. (2012) finding that (1) in absolute values, the errors are increasing in the shock $s_{t}$; (2) for a two standard deviation shock to the stochastic steady state, the errors are smaller than $\$ 1$ of error for $\$ 1,000,000$ spent in consumption. Since a two standard deviation shock is slightly larger than the shock during the Great Depression, these errors are clearly very small. Programs are available upon request.

${ }^{18}$ Algebra details are available in Online Appendix O.2.
} 
shock. In keeping with the theoretical results in Section 3, we study both the current response to a shock and also the lagged response one generation later. Second, based on the estimated policy functions from the calibrated model we study the predicted response to the large productivity shock during the Great Depression. We also provide evidence on intergenerational transfers and compare them to the quantities predicted by the model. Finally, we describe the time paths of human and physical capital, wages and savings to shed additional light on the workings of the model.

We find that the quantitative responses in the model are economically significant. For example, the elasticity of fertility to a contemporaneous productivity shock is 0.94 , while the elasticity one period later is 0.78. Even though the size of this response is economically significant, we show that standard recessions will have rather modest effects on fertility. Large recessions, such as the Great Depression, have important and long lasting effects on fertility choices, however.

We therefore turn to the historical record of the United States and study the predicted response of fertility to the productivity busts and booms over the 20th century. To do so, we must first construct a series of shocks to feed into the model. It is not obvious how to do this in a realistic manner. On the one hand, the model assumes that the shock for the current period is realized at the beginning of the period. Effectively, this means that individuals know what the sequence of annual shocks will be over the next 20 years. Even with highly correlated shocks at annual frequency, this assumption seems extreme. Another alternative is to decrease the length of a period. This necessarily increases the size of the state space. Even decreasing the period length to 10 years, for example, while maintaining the i.i.d. assumption increases the size of the endogenous state space significantly. The reason is that, in order to keep a reasonable distance across generations (e.g., 20 years), one would have to address the timing of births (between age 20-30 versus 30-40) more seriously. This is not an easy problem (see Caucutt et al. (2002), Doepke et al. (2015) and Sommer (2010) for examples). ${ }^{19}$ Relaxing the i.i.d.

\footnotetext{
${ }^{19}$ If one assumes that people are only fertile during the first period of adulthood, children would remain young for two periods. This would mean that when the children of one dynasty are in their second period of childhood, another dynasty would be making fertility decisions. In this case, we would have two overlapping dynasties who interact in goods and credit markets. This doubles the number of generations alive at any point in time. Since the state space consists of physical capital as well as the number and human capital of each generation alive, the state space almost doubles as well. If one assumes that people are fertile for two periods (age 20-30 and 30-40), then either all children become adults at the same time or each parent has two types of children growing up at different times. In the first case, some children become adults at age 10, which is an undesirable assumption. In the second case, the number of types of descendants of one dynasty explodes exponentially. Again, since the state space consists of physical capital as well as the number and human capital of each generation alive, the state space explodes similarly.
} 
assumption - which might be required for 10- as opposed to 20-year periods - adds another state variable. Thus, there are technical difficulties in following the strategy of decreasing the period length.

Because of this, we present results of alternative methods for constructing the relevant series of productivity shocks for TFP for the 20th century. First, because the data show that, over the period 1940 to 1980, at least 60 percent of all births are to women aged 20 to $30,{ }^{20}$ we assume that women have all their children between the ages of 21 and 30 . As our baseline experiment, we therefore assume that the relevant productivity shock is the average value in the data over that 10 year period. In Online Appendix O.3.1, we assume that women have children uniformly between the ages of 21 and 40 . We therefore use the average productivity shock for that 20 year period. In our baseline experiment, a shock to TFP of the size of the Great Depression gives rise to a contemporaneous baby bust that accounts for 58 percent of the reduction in TFR seen in the data. Furthermore, the model prediction of the lagged response to such a shock is a Baby Boom. Combined with the productivity boom in the 1950s, the predicted size of the Baby Boom is 77 percent of the actual size of the Baby Boom observed in the data.

Regarding intergenerational transfers, we use estate data from Piketty and Saez (2001, 2003) and find that, as predicted by the theory, smaller cohorts tend to receive larger transfers per recipient. The evidence is imperfect in many ways; we thoroughly discuss these issues below.

Finally, we describe the time paths of physical and human capital, wages and savings in order to better understand fluctuations in fertility and transfers in this model compared with those of the simple model in Section 3.

\subsection{Parameterization}

Below, we set parameters to match moments for the period 1991 to 2010. A number of these parameters $\left(\alpha, \delta, \gamma, \sigma_{s}, \sigma, \beta, A^{1}, A^{2}, b, \zeta, \nu\right)$ are set using direct estimates in the data or common values in the literature. The remaining parameters $(\phi, \psi, \theta)$ are calibrated to jointly match the average capital-output ratio, population growth and expenditures on children generated by the model to their counterparts in the data.

Production function, Depreciation and Productivity shocks: The share of capital in output and is set to $\alpha=0.33$ while $\delta$, the depreciation rate, is set to $\delta=1-(1-0.088)^{20}$ following Chari et al. (2007). Furthermore, $\gamma$ is the trend productivity growth rate for a 20 -year period and $s_{t}$ is the productivity shock which we assume to

\footnotetext{
${ }^{20}$ See Vital Statistics of the United States, Table 1-7.
} 
be i.i.d. over time. ${ }^{21}$ For computational reasons, it is convenient to assume a functional form for the distribution of productivity shocks, $s_{t}$. We assume that $\ln \hat{s}_{t} \sim N\left(0, \sigma_{s}^{2}\right)$ where $\hat{s}_{t}=s_{t} e^{\sigma_{s}^{2} / 2}$. As such, $E\left(s_{t}\right)=1$ and $\operatorname{Var}\left(s_{t}\right) \approx \sigma_{s}^{2}$. Thus, the parameters of the production function to be determined are $\gamma$ and $\sigma_{s}$.

The growth rate of productivity, $\gamma$, and the standard deviation of productivity shocks, $\sigma_{s}$, are calculated from the annual TFP series from Chari et al. (2007), who use NIPA data from 1900 to 2000, which we extended to the year 2010. First, we compute the linear trend in productivity by running the following ordinary least-squares regression on annual data:

$$
\ln T F P_{t}=\xi_{0}+\xi_{1} t+\epsilon_{t}
$$

We find that $\xi_{1}=0.0151$ therefore setting $\gamma=\left(e^{\xi_{1}}\right)^{20}=1.0153^{20}$. That is, productivity grows at an average of 1.53 percent per year from 1900 to $2010 .^{22}$

To pin down the value of $\sigma_{s}$ several steps are required. The question is: how does the shock, $\hat{s}_{t}$, relate to the error terms, $\epsilon_{t}$, in the equation above? For our baseline experiment, we assume that the relevant shock affecting fertility decisions is a 10-year shock corresponding to a given cohort's most fertile years, namely ages 20 to 30 . We therefore define the shock for the generation fertile in period $j$, as $\ln \hat{s}_{j} \equiv \ln \left(\sum_{t=0}^{9} e^{\epsilon_{j+t}}\right)-$ $\mu$ where $\mu=E\left[\ln \left(\sum_{t=0}^{9} e^{\epsilon_{j+t}}\right)\right]$. To approximate the standard deviation, $\sigma_{s}$, we assume that $\epsilon_{t}$ follows an AR1 process and estimate

$$
\epsilon_{t}=\rho_{0}+\rho_{1} \epsilon_{t-1}+z_{t}
$$

where $z_{t} \sim N\left(0, \sigma_{z}\right)$. We then simulate a long series of $\left\{\epsilon_{t}\right\}$, compute a series $\left\{\ln \hat{s}_{j}\right\}$ and calculate its standard deviation to get $\sigma_{s}=0.07$. As constructed, the series, $\ln \hat{s}_{j}$, is not exactly normally distributed, of course. However, for all simulations, the KolmogorovSmirnov test produces a $p$-value of about 0.4. This means that the test would fail to reject the null hypothesis that the distribution of $\ln \hat{s}_{j}$ is normal at any reasonable significance level. Hence, assuming normality should provide a good approximation.

Preference Parameters: Throughout, we assume that $\eta=1-\sigma$ and set $\sigma=3$ following Mateos-Planas (2002), Scholz and Seshadri (2009) and Jones and Schoonbroodt

\footnotetext{
${ }^{21}$ This is a reasonable approximation for long movements in labor productivity across generations, which are 20 years apart.

${ }^{22}$ An alternative detrending method would be to use a Hodrick-Prescott filter, instead. However, the appropriate value for the smoothing parameter is unclear given that we are interested in long fluctuations, rather than quarter-to-quarter or annual deviations from trend. In any case, for a sufficiently low smoothing parameter, the resulting productivity shocks would typically be smaller. Assuming that the growth rate of productivity is constant in the model while using HP productivity shocks would result in smaller fertility responses in the experiments below.
} 
(2010b), among others. The discount factor is set to $\beta=0.96^{20}$. From the joint calibration described below, we derive an altruism factor of $\phi=1.05474^{20}$.

Human capital and Effective labor: $A^{1}$ and $A^{2}$ are the permanent productivity parameters for young and old workers, respectively. From the life-cycle earnings profiles in Hansen (1993) and Huggett (1996), we gather that wages of workers ages 40 to 60 are about 25 percent higher than those ages 20 to 40 . We therefore normalize $A^{1}=10$ and choose $A^{2}=1.25 * A^{1}$. From the joint calibration described below, we derive an elasticity of effective labor to human capital of $\psi=0.6838$.

Costs of Children and of their Human capital: Estimating the cost of children is not an easy task. The U.S. Department of Agriculture (USDA) provides estimates of yearly expenditures on children since 1960. We use these estimates to formulate a target in the joint calibration below. This leads to a goods cost of children of $\theta=$ 0.629. Schoonbroodt (2016) uses data from the PSID-CDS 1997 time diaries to compute active and passive time spent with children, distinguishing between child care during and outside of typical work hours. Because the only alternative activity in our model is work, we use the estimates during typical work hours (defined as $8 \mathrm{am}$ and 6pm, Mondays through Fridays). Since the PSID-CDS data are only available for children under the age of 12 , we extrapolate time spent with children after age 12 . To do so, we use the average time spent for two six-year age groups, namely ages 0 to 5 and ages 6 to 11 . We then compute the ratio of the latter to the former and assume that this ratio is the same for time spent with children ages 12 to 17 relative to ages 6 to 11 . Schoonbroodt (2016) reports that parents of children age 0 to 5 spend a combined 21.07 hours per week per child (14.41 hours in active care and 6.66 hours in passive care), while parents of children age 6 to 11 spend a combined 10.38 hours per child per week (5.25 hours in active care and 5.14 hours in passive care). Assuming a 50 hour workweek (8am to $6 \mathrm{pm}$, Monday through Friday), the household's time endowment is 100 hours. Hence, we set $b=\left(21.07+10.38+10.38 *\left(\frac{10.38}{21.07}\right)\right) / 100=0.1219 .{ }^{23}$ Regarding the cost of human capital, we assume that there is no time cost $\left(\zeta_{t}=0\right)$, but rather only a goods cost $\left(\nu_{t}=1\right)$. Given all other parameters, this goods cost can be normalized.

Joint Calibration: The parameters to be jointly calibrated are the altruism factor, $\phi$, the elasticity of effective labor to human capital, $\psi$, and the goods costs of children. The three calibration targets we pick are the annual population growth rate of $0.598,{ }^{24}$ the

\footnotetext{
${ }^{23}$ See Schoonbroodt (2016) Tables A.17 and A.19, column 1, T.W.H., Parents rows.

${ }^{24}$ This is the average observed in the data from 1991 to 2010 from the U.S. National Center for Health Statistics,Vital Statistics of the United States, and National Vital Statistics Reports (NVSR), Births minus Deaths.
} 
steady state capital-output ratio of $2.52,{ }^{25}$ and goods costs as a fraction of household income of 16.37 percent. $^{26}$

Hence, we look for a combination of parameters such that $E(n)=1.005975^{20}$, $E(K / Y)=2.52$ and $\frac{\theta}{w^{1}(1-b n)}=0.1637$. Now, while jointly matched, the three target moments are each particularly sensitive to one of the three parameters. In particular, population growth, $n$, is particularly sensitive to the degree of altruism, $\phi$. Similarly, the capital-output ratio is particularly sensitive to the elasticity of effective labor to human capital, $\psi$. Goods costs as a fraction of income, $\frac{\theta}{w^{1}(1-b n)}$, not surprisingly, are particularly sensitive to the goods cost parameter, $\theta$. These sensitivities make the calibration algorithm straightforward.

Summary: These parameters are summarized in Table 2.

Table 2: Parameter Values, Baseline (1991-2010)

\begin{tabular}{c|l|l|c|l|l}
\hline \hline Param. & Value & Meaning & Param. & Value & Meaning \\
\hline$\alpha$ & 0.33 & cap. share in output & $\delta$ & 0.8415 & depreciation rate \\
$\gamma$ & $1.0153^{20}$ & prod. growth rate & $\sigma_{s}$ & 0.07 & st. dev. prod. shocks \\
$\psi$ & 0.728 & returns to human cap. & $\sigma$ & 3.00 & int. elast. of subst. \\
$\beta$ & $0.96^{20}$ & discount factor & $\phi$ & $1.0547^{20}$ & altruism factor \\
$A^{1}$ & 10.00 & labor prod. age 1 & $A^{2}$ & 12.5 & labor prod. age 2 \\
$\theta$ & 0.629 & goods cost children & $b$ & 0.122 & time cost children \\
$\nu$ & 1.00 & goods cost human cap. & $\zeta$ & 0.00 & time cost human cap. \\
\hline \hline
\end{tabular}

With this parameter configuration, completed fertility in steady state is $C F R_{s s}=$ $2 E\left(n_{t}\right)=2.252$. The present value of transfers (per child) from parents to children is positive and of the order of 40 percent of the present value of life-time wage income in steady state. Note that children only care about the present value of transfers; age-specific transfers are indeterminate. One can show that fertility levels and their

\footnotetext{
${ }^{25}$ This is the average between 1991 and 2010 from NIPA, following the calculations by Chari et al. (2007) extended to the year 2010.

${ }^{26}$ Since 1960, the USDA provides estimates of yearly expenditures on children from birth through age 17 for husband-wife and single-parent families with one, two or three and more children using data from the latest Consumer Expenditure Survey (CEX), updated to current dollars using the Consumer Price Index (CPI). Lino (2002) estimates expenditures by region, broad income group and three-year age groups of children. We use Lino (2002) which contains data from the 1990-92 CEX, updated to 2000 dollars. Here, we focus on the overall U.S. estimates for husband-wife middle-income two-children families who, on average, make $\$ 50,600$ per year. Their total expenditure is $\$ 165,630$. Spread over 20 years, this gives an average annual expenditure of $\$ 8,282$ per child, which constitutes 16.37 percent of annual income.
} 
Table 3: Impulse Response (in percent and levels), Baseline

\begin{tabular}{c|c|c|c|c}
\hline \hline \multicolumn{2}{c|}{$\%$} & \multicolumn{3}{c}{$(\mathrm{C}) \mathrm{TFR}$ Levels } \\
\hline $\begin{array}{c}\text { Initial Deviations } \\
\text { (a) }\end{array}$ & $\begin{array}{c}\text { Lagged } \\
\text { (b) }\end{array}$ & $\begin{array}{c}\text { Initial } \\
\text { (c) }\end{array}$ & $\begin{array}{c}\text { Lagged } \\
\text { (d) }\end{array}$ & $\begin{array}{c}\text { Steady St. } \\
\text { (e) }\end{array}$ \\
\hline 1.0981 & -0.7922 & 2.2778 & 2.2352 & 2.252 \\
\hline \hline
\end{tabular}

fluctuations only depend on $\phi \beta$, while savings and transfers depend on $\phi$ (altruism factor) separately from $\beta$ (discount factor). Disentangling the two is rather difficult, due to the arbitrary nature of the timing of transfers, which gives age-specific savings a likewise arbitrary nature. Therefore, it is possible to set $\beta$ to a higher value and adjust $\phi$ so that $\beta \phi$ remains unchanged, thereby decreasing the level of transfers while leaving the fluctuation results unchanged.

\subsection{Model impulse responses}

Given the parameter values from the previous section, we calculate the decision rules in the model. These can then be used to estimate model responses to productivity shocks of different sizes. The results are summarized in Table 3. The first two columns report the elasticities (at the steady state) of (a) current and (b) lagged fertility to productivity shocks. The next two columns give the (c) contemporaneous and (d) lagged changes in fertility levels that the model predicts will result from a 1-percent increase in productivity. Column (e) recalls the steady state level of completed fertility.

As the table indicates, the fertility response to a 1-percent productivity shock generates a 1.1 percent contemporaneous increase in fertility (column (a)) with a lagged decrease of 0.79 percent one period later (column (b)). These magnitudes can be compared to the regression results shown in Table 1. In particular, column (a) is to be compared with $\lambda_{1}$ and column (b) with $\lambda_{2}$. Thus, if the model fit the data perfectly, we would see 0.83 in column (a), and -0.84 in column (b). That is, the contemporaneous effect is greater in magnitude than in the perfect-fit case, while the lagged effect is lesser in magnitude.

To get a sense of the size of these effects, note that a 1-percent decrease in productivity over a 10-year period roughly corresponds to a recession where GDP is 5 percent below trend for two years. This would decrease fertility by about 0.025 children per woman ((c)-(e)), with a subsequent baby boom of about $0.018((\mathrm{e})-(\mathrm{d}))$. Thus, the 
Table 4: Productivity shocks (in percent), Baseline

\begin{tabular}{l|r|r|r|r|r}
\hline \hline Decade & $1910 \mathrm{~s}$ & $1930 \mathrm{~s}$ & $1950 \mathrm{~s}$ & $1970 \mathrm{~s}$ & $1990 \mathrm{~s}$ \\
Productivity Shock & -1.82 & -13.09 & 7.49 & 5.68 & -4.51 \\
\hline \hline
\end{tabular}

quantitative effects on (completed) fertility of a normal sized recession would be quite modest. As we shall see below, the model predicts that a recession the size of the Great Depression prompts a much larger response.

\subsection{The U.S. Great Depression}

In this section, we use the historical record of the actual series of productivity shocks in the U.S. to study the predicted fertility response to the productivity busts and booms of the 20th century. We also compare the prediction of the model for intergenerational transfers with evidence from estate data. Finally, we discuss the time paths of physical and human capital, wages and savings.

\subsubsection{Fertility}

To focus on the effects of the Great Depression, we start the model simulation so that fertility decisions are made in the 1910s, 1930s, 1950s, 1970s and 1990s. ${ }^{27}$ We assume that the economy is at its steady state age-distribution at the beginning of the 20th century.

The relevant series of productivity shocks, $s_{t}$, is shown in Table 4 and results are shown in Figure 5. The model predicts that fertility is 11.1 percent below its steady state during the 1930s. In the data, TFR is actually 19 percent below trend in the 1930s. Thus, the model captures a significant fraction of this movement. This is primarily due to the large, negative shock of 13 percent during the Great Depression of the 1930s the dynasty's fertility in the 1910s is almost at its steady state value and, hence, lagged effects are minimal in the 1930s.

On the other hand, low fertility during the 1930s implies a Baby Boom for the next cohort in this dynasty, which takes place in the 1950s. The model prediction is an increase in fertility above its steady state of 15.7 percent. These predictions result

\footnotetext{
${ }^{27}$ This dynasty is the most affected by the Great Depression. Note that TFR and CFR are equivalent in our model because one period closely corresponds to fertile ages. We therefore choose to plot our model simulations against the TFR measure of fertility. In a previous version of this paper, Jones and Schoonbroodt (NBER 2010, Section 4.3.2), we present an alternative mapping between model and data by constructing overlapping dynasties in order to distinguish between a measure of CFR and TFR.
} 
Figure 5: Percent Deviations in Total Fertility Rate

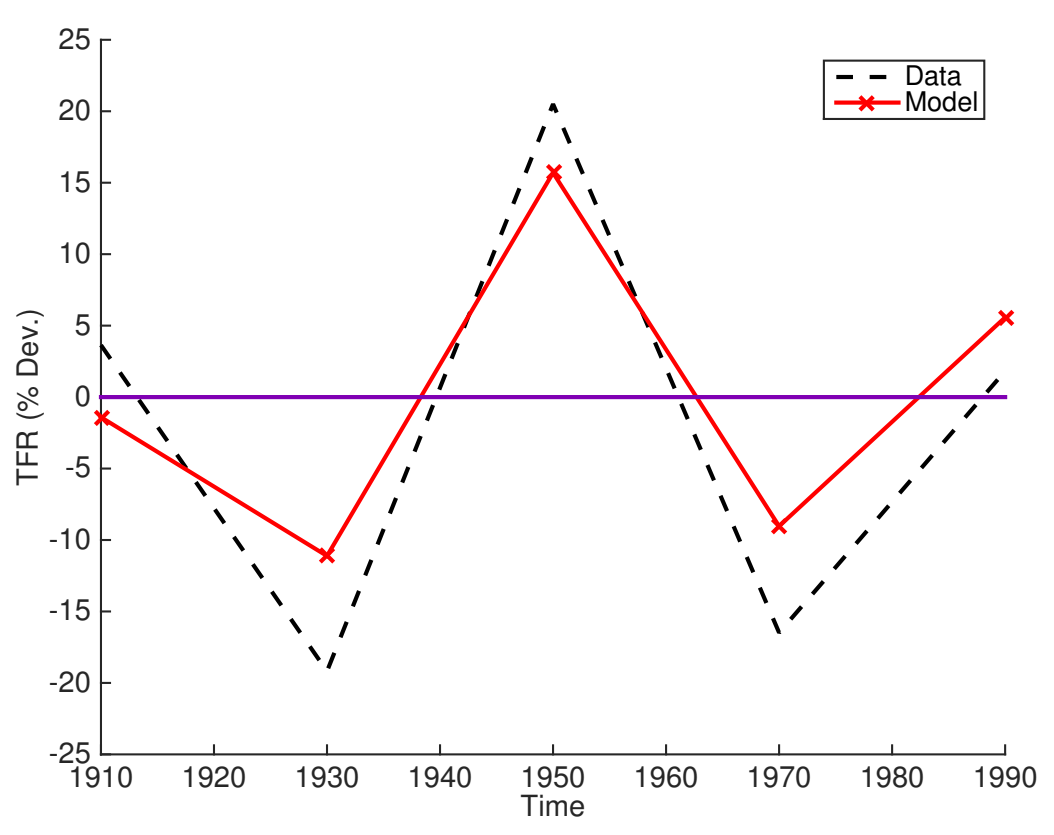

from a combination of the fertility response to the baby bust as well as the 7.5 percent productivity boom in the 1950s. For comparison, the Baby Boom in the TFR data is 20.5 percent above trend during these years.

Hence, in response to productivity shocks, the model accounts for 58 percent of the baby bust and for 77 percent of the Baby Boom in TFR. In subsequent periods, TFR in the model keeps fluctuating - 9 percent below trend in the late 1970s (due to the prior Baby Boom, dampened by the 5.7 percent increase in TFP). The corresponding movements in the data on TFR are 16.5 percent below trend. The increase in fertility in the 1990s of 1.8 percent above trend in the data is also captured by the model, which predicts a larger increase of 5.6 percent.

\subsubsection{Intergenerational Transfers}

Evidence on intergenerational transfers going back to the early 20th century is hard to come by. To get at least suggestive evidence, we use estate data by Piketty and Saez (2001, 2003). In line with our theory - though at the cost of a few assumptions - this data suggest that cohort size and transfers per recipient are inversely related.

Piketty and Saez $(2001,2003)$ use estate tax returns since 1916 to estimate estates of the top fractiles in the U.S. The data we use are the average size of estates in the top 
2 percent in 1998 dollars (Table C3, the largest fractile available). They apply standard Pareto interpolation techniques to figures for the number of descendants in each year ((Historical Statistics of the US (before 1970) and Statistical Abstract of the U.S., (after 1970))), as well as the percentage of said descendants who filed estate taxes and their corresponding estate sizes (IRS) to estimate these average estates. This produces a series from 1916 to 1997 with values for almost every year. For the missing years, we assume that the average estate is the same as in the last year for which the data are available. ${ }^{28}$

In our quantitative model, transfers grow exogenously at the same rate as output, consumption, etc., namely, 1.53 percent per year $\left(\gamma=1.0153^{20}\right)$. We therefore detrend the data series at that same rate. The resulting series shows a decreasing trend with some rather minor fluctuations. This is in line with the findings in Piketty and Saez (2001, 2003) and Kopczuk and Saez (2004), who show that estates have been declining relative to wage income, for example.

Next, we want to derive a measure of transfers per child. Assuming that most of those who die and leave bequests are between age 60 and 70 and that they have children between the ages of 20 and 30, they would have had children about 40 years before dying. ${ }^{29}$ We use averages per decade to smooth out some of the year-to-year fluctuations. Furthermore, we assume that the swings and variation in fertility were the same for the top 2 percent as for the general population, and that estates are equally distributed across children. ${ }^{30}$

Given these assumptions and adjustments, we divide the estates of the top 2 percent by the fertility rate four decades before the estate was recorded. The resulting series is the average bequest per child by birth cohort for people born between 1880 and 1959

${ }^{28} \mathrm{~A}$ few words of caution are in order. First, the age of descendants is 24 and above. We make assumptions about death rates below. Second, the percentage of descendants for whom estate taxes are filed varies over time due to economic and tax code changes. Early on, less than 1 percent filed, while in the 1970s, about 11 percent filed (see Table C2). Of course, only estates for which taxes were filed appear in these data, i.e. the upper tail. Third, transfers in the model would also include inter-vivos gifts. Kopczuk and Saez (2004), however, argue that such gifts are a small fraction of overall estate wealth, namely 2 to 3 percent. Tax avoidance through gifts, they argue, is also not as effective as one might think, because gifts occurring within 2 to 3 years of death were always part of the estate tax base.

${ }^{29}$ Because richer people tend to die later and bear children later, results would have been the same assuming that most of them die between the ages of 70 and 80 and had children between the ages of 30 and 40. Given this, a four decade time difference between childbirth and bequests seems to be a reasonable assumption. Just to be sure, we also applied a five decade gap and got similar results. However, because the data end in 1997, we could only go back to the 1940s cohort in this case. All the data in Piketty and Saez (2001, 2003), except Appendix C - the data we use - were updated to 2011.

${ }^{30}$ Light and McGarry (2004) find that only 8 percent of their sample intends to make unequal bequests. Contrary to what is found with bequests, inter-vivos transfers are observed to vary according to the child's income. Altonji et al. (1997) find that money transfers tend to reduce inequality in household incomes. The better off a child is financially, the less likely he is to get help from his parents. 
Figure 6: Intergenerational Transfers

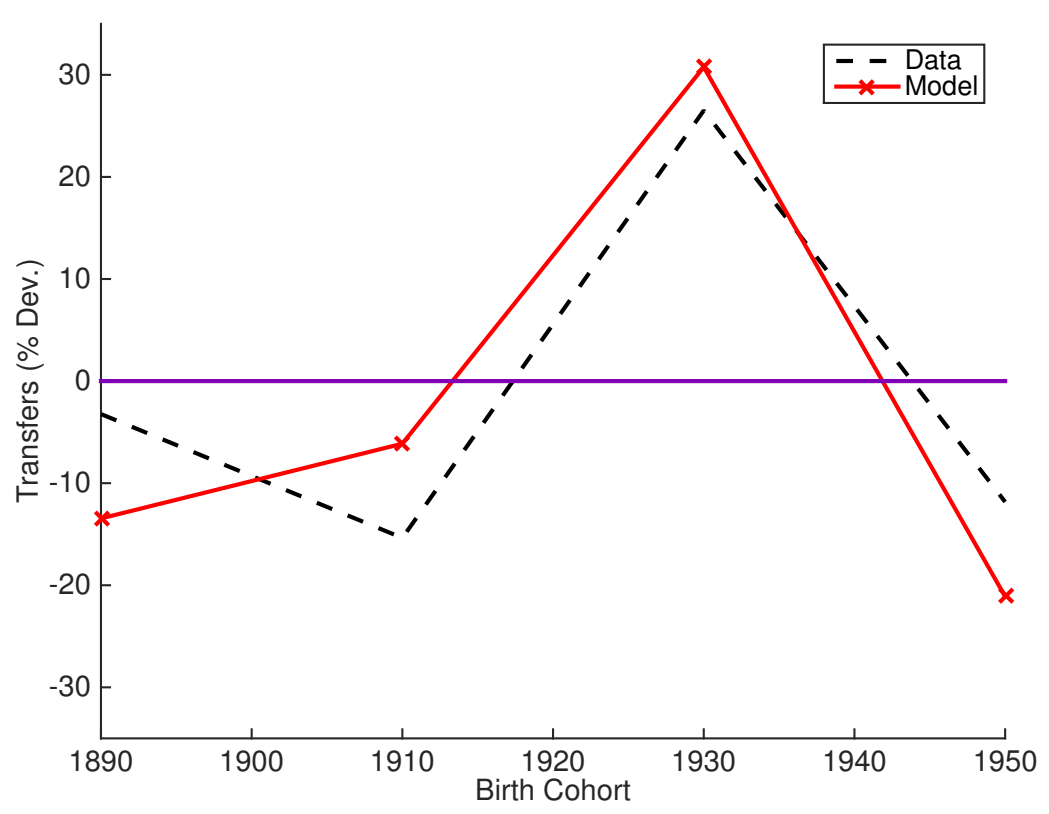

(labeled 1880s to 1950 s).

Although the level of bequests of the top 2 percent is not representative of the entire population, we are primarily interested in the changes in bequests. We can therefore compute the average transfer from the 1880 s to the 1950 s cohorts, proceeding to examine percent changes relative to this average over time.

Figure 6 plots this series together with the relevant model predictions, where the $1890 \mathrm{~s}$ birth cohort makes transfers in the $1930 \mathrm{~s}$, etc. That is, we plot $t_{t}^{2} / t_{s s}^{2}$, where $t=1930 \mathrm{~s}, 1950 \mathrm{~s}, 1970 \mathrm{~s}, 1990 \mathrm{~s}$ which corresponds to the 1890s, 1910s, 1930s and 1950s birth cohorts. As shown in the figure, percent changes and transfers track the movements in bequest data fairly closely. With the exception of the 1910 cohort, percentage changes are larger in the model than in the data, however. In particular, the cohort born in the 1930s - the time when fertility was at its lowest point - received the largest bequests/transfers, while the cohort born in the 1950s - the early Baby Boom cohortreceived much smaller bequests/transfers. As we show in the next subsection, this is partly due to the mechanism explained in Section 3 and partly to the low (high) level of human capital of the 1930s (1950s) birth cohort.

vspace-10pt 


\subsubsection{Savings, wages, physical and human capital}

Now, how does the mechanism in Section 3 change with the addition of alternative investments? Figure 7 plots the time paths of (a) human capital per young worker, $h$, (b) physical capital per old worker, $k$, (c) wages, $w, w^{1}, w^{2}$ and (d) savings, $x^{1}, x^{2}$.

Recall that, in stochastic endogenous growth models, the ratio of capital per unit of effective labor is constant over the cycle. Fluctuations therefore differ only in percentage terms if depreciation rates differ. In our model, human capital does not depreciate over a person's working life, but fully depreciates as people retire, while physical capital depreciates continually. The reason why the ratio of capital per unit of effective labor is not completely constant here is because effective labor is also affected by the current shock through the time cost of children. When fertility is low, effective labor is relatively high and, hence, the ratio of physical to human capital is relatively low. Still, these deviations amount to less than 1 percent of the steady state value of capital per unit of effective labor. It is therefore unsurprising to see similar fluctuations in panels (a) and (b) of Figure 7.

Figure 7c plots wages per unit of effective labor, $w$, which track productivity shocks throughout; this is because the capital to effective labor ratio does not fluctuate much over time. In the 1930s, all workers have already accumulated human capital. Therefore, wages of young and old workers, $w^{1}$ and $w^{2}$, also simply track productivity shocks in the 1930s. Because of low productivity during this period, alongside the baby bust, we also see low investments in human and physical capital. This is reflected in relatively low wages of the cohort born in the 1930s, who are young workers in the $1950 \mathrm{~s}\left(w_{1950}^{1}\right.$ compared to $w_{1950}$ and $\left.w_{1950}^{2}\right)$ and old workers in the $1970 \mathrm{~s}\left(w_{1970}^{2}\right.$ compared to $w_{1970}$ and $\left.w_{1970}^{1}\right)$. Hence, besides the mechanism discussed in Section 3, another reason for larger transfers to the baby bust children born in the 1930s is that their lifetime wages are relatively low. Wages of old workers in the 1950s still track productivity shocks because investments in human capital were made before the Great Depression. In the same vein, the productivity boom in the 1950s, alongside the Baby Boom, encourages larger investments in human and physical capital. This is reflected in relatively high wages of the cohort born in the 1950s, who are young workers in the $1970 \mathrm{~s}$ ( $w_{1970}^{1}$ compared to $w_{1970}$ and $\left.w_{1970}^{2}\right)$ and old workers in the 1990s $\left(w_{1990}^{2}\right.$ compared to $w_{1990}$ and $\left.w_{1990}^{1}\right)$. The relatively high lifetime wages that result for the Baby Boomers is another reason for the relatively low intergenerational transfers they receive from their baby bust parents.

Finally, savings at age $a=1$ and age $a=2$ also partially track productivity shocks. Savings at age $a=1$ are more volatile because (1) young workers also have to invest in 
Figure 7: Savings, Wages, Physical and Human Capital

(a) Human capital (per young worker)

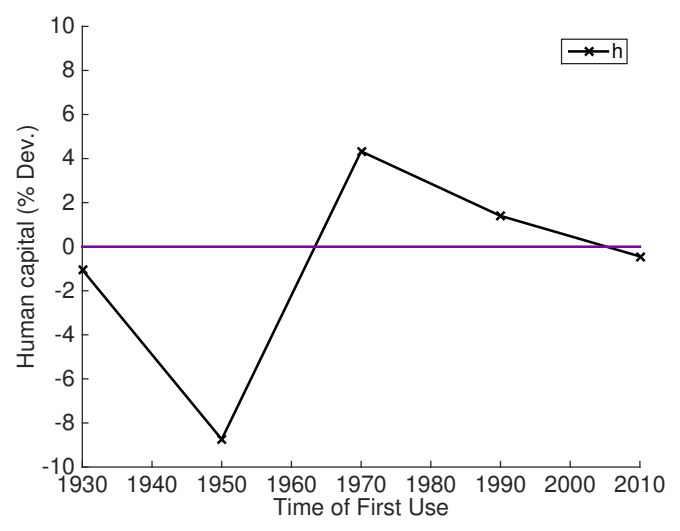

(c) Wages

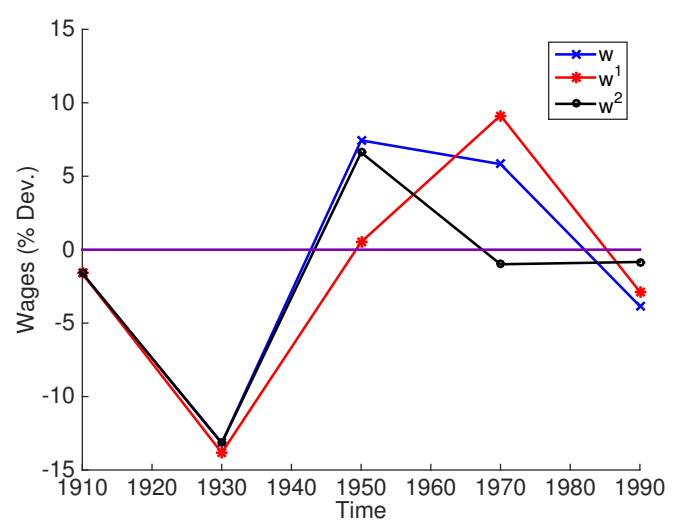

(b) Physical capital (per old worker)

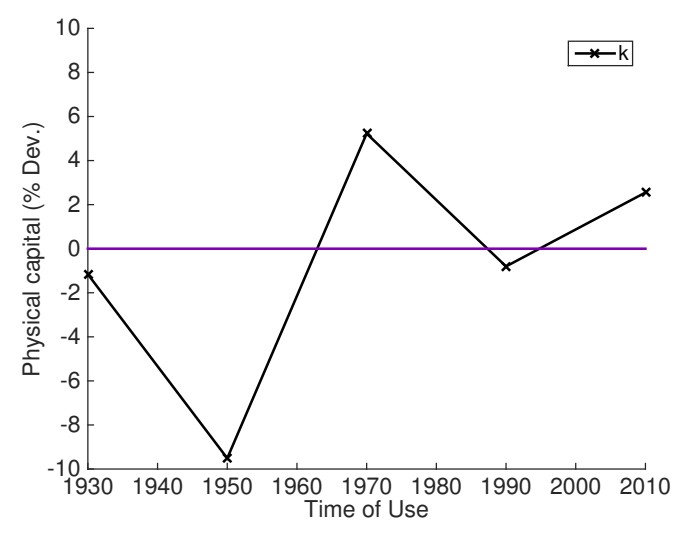

(d) Savings

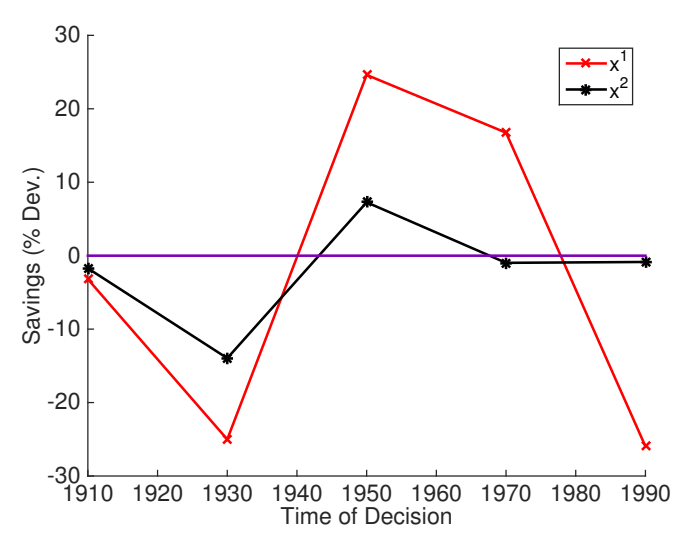

children and their human capital and (2) transfers from the parents arrive only at age $a=2$. Since we arbitrarily set transfers at age $a=1$ equal to 0 (given that people only care about the present value of transfers), the savings levels and their fluctuations are also somewhat arbitrary.

\subsubsection{Sensitivity}

In this section, we summarize the sensitivity analysis presented in Online Appendix O.3. In Section O.3.1, we assume that women have children uniformly between the ages of 21 and 40 . We therefore use the average productivity shock for that 20 year period. Indeed, the model captures less of the baby bust in this case. The Baby Boom remains large because the average shock in TFP was also high in the 1960s. Because this alternative is at the opposite extreme of the baseline - assuming that women have children uniformly during this time - the two experiments together should give us reasonable bounds on the 
extent to which the model can account for the fertility fluctuations in the U.S. over the 20th century. In Section O.3.2, we change the length of the period to thirty years so that fertility decisions are made between the ages of 31 and 40. This actually increased the size of the responses. In Section O.3.3, we vary the intertemporal elasticity of substitution. In particular, when, given $\sigma=0.5$, we recalibrate $\phi, \theta$ and $\psi$; the model still captures 50 percent of the baby bust in the 1930s and 70 percent of the Baby Boom in the 1950s, which is a promising indication for the robustness of the quantitative results.

\section{International evidence on the Great Depression}

There is a large statistical literature on the cyclicality of fertility. Sobotka et al. (2011) extensively review this literature and analyze several major recessions in detail including the Great Depression, the recession of the 1970s and economic shocks in Central and Eastern Europe after 1989. In their survey of 26 low-fertility countries from 1980-2008, they find that of 62 recessions (defined as a drop in GDP), 50 were followed by a drop in TFR one year later.

In this section, we provide additional statistical evidence. We analyze data for 17 countries during the Great Depression, finding that countries with a smaller Depression in the 1930s tend to have smaller baby busts. Moreover, those with smaller baby busts tend to have smaller Baby Booms in the 1950s, conditional on the economic circumstances in the $1950 \mathrm{~s}$. The latter finding directly relates to our theory and was not considered in Sobotka et al. (2011).

Before we start, several data-related issues should be addressed. These relate to data availability, detrending methods and dealing with war periods. Ideally, we would like to use the same measures of fertility and productivity as we do for the U.S.. However, complete TFR series and consistent TFP measures for the 20th century are only available for few countries (see e.g., Chesnais (1992) for TFR and Cette et al. (2009) for TFP). We therefore use Crude Birth Rates (CBR), mostly from Mitchell (1998), and GDP per capita from Barro and Ursua (2008), instead. ${ }^{31}$ This gives us 17 countries for which we have data from 1900 until $1993 .^{32}$

\footnotetext{
${ }^{31}$ CBR data form 1900 to 1993 were obtained from Mitchell (1998) for all countries except Germany. German data were combined using Chesnais (1992, Appendix A1) for the 1900 to 1943 period and Statistisches Bundesamt (2007) for 1946 to 1993, linearly interpolating 1944 and 1945. All GDP per capita data comes from Barro and Ursua (2008) and is in millions 1990 International Geary-Khamis dollars.

${ }^{32}$ The main issues are as follows. CBR, as opposed to TFR, is sensitive to mortality in certain groups of the population. For example, wars tend to affect total population but not the number of fertile women. GDP per capita, as opposed to TFP or LP, is only an indirect measure of the productivity of the labor force and therefore corresponds to our model to a lesser degree.
} 
As to detrending, we use the same detrending method for CBR as we did for TFR in the U.S., namely a Hodrick-Prescott (HP) filter. While a linear detrending method for log-TFP poses few problems for the U.S., this is not true for all countries we consider. In particular, if one uses linear detrending, countries such as Portugal or Japan show a permanent negative deviation in GDP early in the century and a permanent positive one later on. We therefore also use an HP filter in comparison.

Furthermore, the two world wars affected fertility levels in several ways that are unrelated to our mechanism. For example, men being away to fight prevents some women from having children. Typically, there is rapid catching up as soon as the men return, if they do (e.g., see the period 1943-1946 in U.S. data shown in Figure 3). ${ }^{33}$ The longer the war involvement lasts and the larger the death rate of soldiers, the more unpredictable this effect on fertility rates becomes. Similar issues emerge for GDP data during war periods. For example, a large part of the increase in output in Germany during the war was not for private consumption but rather war-related. We therefore also use dummies for war and years immediately following wars to adjust our measures of deviations in CBR and GDP in comparison to deviations resulting from a simple linear trend and the HP filter. ${ }^{34}$

Given these provisos, we are now ready to analyze sizes of Depressions, baby busts and Baby Booms. First, we aim to determine the correlation between the size of the Depression in the 1930s and the size of the contemporaneous baby bust across countries. Since the timing of the Depression differed across countries, we divide the 1930s into two periods: 1930 to 1934 and 1935 to 1939. We then run eight cross-country OLS regressions, one for each time period, combined with one of four detrending methods. ${ }^{35}$ Let $\widehat{X}_{t}^{i}$ denote the percent deviation from trend in variable $X$ in country $i$ in the five-year period, $t$ :

$$
\widehat{C B R}_{t}^{i}=\lambda_{1, t}+\lambda_{2, t} \widehat{G D P}_{t}^{i}+\varepsilon^{i}
$$

where $t=\{30-34,35-39\}$. The results for each detrending method are given in Table 5 .

As indicated in the table, the coefficient, $\lambda_{2, t}$, is positive for all detrending methods and both time periods. It is larger (with a lower $p$-value) whenever an HP filter is used rather than linear detrending and whenever the effects of wars are taken into account in detrending. Also, for most detrending methods, $\lambda_{2, t}$ is larger in the early 1930 s than in

\footnotetext{
${ }^{33}$ See Vandenbroucke (2014).

${ }^{34}$ For details on our detrending procedures, see Jones and Schoonbroodt (NBER 2010, Appendix A.3).

${ }^{35}$ Tables A.5 to A.8 in Jones and Schoonbroodt (NBER 2010) show the inputs into these regressions, namely, percent deviations from trend in $C B R$ and $G D P$ in the 1930s for each country and each detrending method.
} 
the late 1930 s.

Second, we aim to determine whether a larger baby bust in the 1930s implies a larger Baby Boom in the 1950s, controlling for the GDP deviation in the 1950s. To do this, we run eight cross-country OLS regressions, one for each time period, combined with one of four detrending methods:

$$
\widehat{C B R}_{t}^{i}=\lambda_{3, t}+\lambda_{4, t} \widehat{C B R}_{t-20}^{i}+\lambda_{5, t} \widehat{G D P}_{t}^{i}+\varepsilon^{i},
$$

where $t=\{50-54,55-59\}$. The results for each detrending method are given in Table 6 .

Here, the coefficient $\lambda_{4, t}$ is negative for all detrending methods and both time periods. It is larger in absolute value (with a lower $p$-value) whenever an HP filter is used rather than linear detrending and, for the late 1950s, whenever the effects of wars are taken into account in detrending. Also, $\lambda_{4, t}$ is larger in the early 1930s than in the late 1930s when the effects of wars are not taken into account in detrending; the coefficient is smaller when they are. Similarly to $\lambda_{2, t}$, the coefficient $\lambda_{5, t}$ is positive for all detrending methods and both time periods. However, $p$-values are larger, especially in the early 1950s.

In sum, then, international evidence on the sizes of depressions and baby busts in the 1930s strongly supports our theory; the evidence for the size of the subsequent Baby Boom, though rightly signed, is somewhat weaker. Albanesi (2012) shows that the amount of wartime destruction during WWII was critical in the determining the size and length of the Baby Boom, while Schoonbroodt (2006), Chapter 5, also finds that the variation in war capital destruction relative to war deaths may have played a role in the differential sizes of Baby Booms across countries.

\section{Concluding remarks}

In this paper, we have studied the properties of models of fertility choice with dynastic altruism in which both aggregate shocks and multiple generations are present. We have shown that in simple versions of this class of models, fertility is procyclical and has dampened oscillations when perturbed away from the steady state. Moreover, these effects are quantitatively significant. In calibrated simulations of the model, we find that the decline in fertility in response to a negative shock to income such as the Great Depression in the model is 58 percent of the decline actually seen in the data. Moreover, because of a (mild) productivity boom in the 1950s and early 1960s in conjunction with the oscillatory effects discussed above, the model accounts for 77 percent of the Baby Boom. A testable implication of the theory is that smaller cohorts should get larger transfers per recipient than larger cohorts. Indeed, evidence on estate taxes from Piketty and Saez 
Table 5: Cross-Country: Depressions and Busts, 1930s

\begin{tabular}{|c|c|c|c|c|c|}
\hline \multirow{2}{*}{$\begin{array}{l}\text { Dependent } \\
\text { Variable }\end{array}$} & \multirow{2}{*}{$\begin{array}{l}\text { Independent } \\
\text { Variable }\end{array}$} & \multicolumn{4}{|c|}{ Detrending Method } \\
\hline & & Linear & $\mathrm{HP}$ & $\begin{array}{l}\text { Linear } \\
\text { No war }\end{array}$ & $\begin{array}{c}\text { HP } \\
\text { No war }\end{array}$ \\
\hline \multirow[t]{2}{*}{$\widehat{C B R}_{30-34}^{i}$} & Constant $\left(\lambda_{1,30-34}\right)$ & -0.0522 & -0.0839 & -0.0365 & -0.0446 \\
\hline & $\begin{array}{l}\widehat{G D P}_{30-34}^{i}\left(\lambda_{2,30-34}\right) \\
\text { (p-value) }\end{array}$ & $\begin{array}{l}0.3512 \\
(0.059)\end{array}$ & $\begin{array}{l}0.4253 \\
(0.008)\end{array}$ & $\begin{array}{l}0.3933 \\
(0.084)\end{array}$ & $\begin{array}{l}0.6480 \\
(0.008)\end{array}$ \\
\hline \multirow[t]{2}{*}{$\widehat{C B R}_{35-39}^{i}$} & Constant $\left(\lambda_{1,35-39}\right)$ & -0.0856 & -0.1211 & -0.0716 & -0.0806 \\
\hline & $\begin{array}{l}\widehat{G D P}_{35-39}^{i}\left(\lambda_{2,35-39}\right) \\
(p \text {-value })\end{array}$ & $\begin{array}{l}0.2118 \\
(0.441)\end{array}$ & $\begin{array}{l}0.5743 \\
(0.005)\end{array}$ & $\begin{array}{l}0.2482 \\
(0.335)\end{array}$ & $\begin{array}{l}0.5554 \\
(0.004)\end{array}$ \\
\hline
\end{tabular}

Table 6: Cross-Country: Busts and Booms, 1950s vs. 1930s

\begin{tabular}{|c|c|c|c|c|c|}
\hline \multirow{2}{*}{$\begin{array}{l}\text { Dependent } \\
\text { Variable }\end{array}$} & \multirow{2}{*}{$\begin{array}{l}\text { Independent } \\
\text { Variable }\end{array}$} & \multicolumn{4}{|c|}{ Detrending Method } \\
\hline & & Linear & $\mathrm{HP}$ & $\begin{array}{l}\text { Linear } \\
\text { No war }\end{array}$ & $\begin{array}{c}\text { HP } \\
\text { No war }\end{array}$ \\
\hline \multirow[t]{3}{*}{$\widehat{C B R}_{50-54}^{i}$} & Constant $\left(\lambda_{3,50-54}\right)$ & 0.0477 & 0.0203 & 0.0853 & 0.0506 \\
\hline & $\begin{array}{l}\widehat{C B R}_{30-34}^{i}\left(\lambda_{4,50-54}\right) \\
\text { (p-value) }\end{array}$ & $\begin{array}{r}-0.2795 \\
(0.229)\end{array}$ & $\begin{array}{r}-0.3680 \\
(0.058)\end{array}$ & $\begin{array}{l}-0.1527 \\
(0.634)\end{array}$ & $\begin{array}{r}-0.2792 \\
(0.372)\end{array}$ \\
\hline & $\begin{array}{l}\widehat{G D P}_{50-54}^{i}\left(\lambda_{5,50-54}\right) \\
\text { (p-value) }\end{array}$ & $\begin{array}{l}0.2181 \\
(0.171)\end{array}$ & $\begin{array}{l}0.3316 \\
(0.092)\end{array}$ & $\begin{array}{l}0.2571 \\
(0.208)\end{array}$ & $\begin{array}{l}0.2034 \\
(0.428)\end{array}$ \\
\hline \multirow[t]{3}{*}{$\widehat{C B R}_{55-59}^{i}$} & Constant $\left(\lambda_{3,55-59}\right)$ & 0.0960 & 0.0296 & 0.0680 & 0.0296 \\
\hline & $\begin{array}{l}\widehat{C B R}_{35-39}^{i}\left(\lambda_{4,55-59}\right) \\
\text { (p-value) }\end{array}$ & $\begin{array}{r}-0.0973 \\
(0.714)\end{array}$ & $\begin{array}{c}-0.2854 \\
(0.181)\end{array}$ & $\begin{array}{r}-0.4048 \\
(0.143)\end{array}$ & $\begin{array}{r}-0.5748 \\
(0.020)\end{array}$ \\
\hline & $\begin{array}{l}\widehat{G D P}_{55-59}^{i}\left(\lambda_{5,55-59}\right) \\
(p \text {-value })\end{array}$ & $\begin{array}{l}0.6052 \\
(0.012)\end{array}$ & $\begin{array}{l}1.0424 \\
(0.004)\end{array}$ & $\begin{array}{l}0.4029 \\
(0.045)\end{array}$ & $\begin{array}{l}0.4887 \\
(0.046)\end{array}$ \\
\hline
\end{tabular}


(2001, 2003) suggests that the small cohort born in the 1930s received above average transfers, while the large cohort born in the 1950s received below average transfers.

Future work could apply this mechanism to other historical events, such as the differential experience between the South and the North during and after the American Civil War or the fertility experience across Eastern European countries after 1989.

Furthermore, a more detailed look at age-specific fertility rates in a model that allows for shorter periods and overlapping lives could shed more light on the sources of the onset of the Baby Boom in the late 1940s and its end in the late 1960s.

\section{References}

Albanesi, Stefania, "Maternal Health and Fertility: An International Perspective," WORLD DEVELOPMENT REPORT, Background Paper, The World Bank 2012.

- and Claudia Olivetti, "Maternal Health and the Baby Boom," Quantitative Economics, 2014, 5 (2), 225-269.

Altonji, Joseph G., Fumio Hayashi, and Laurence J. Kotlikoff, "Parental Altruism and Inter Vivos Transfers: Theory and Evidence," The Journal of Political Economy, 1997, 105 (6), 1121-1166.

Alvarez, Fernando E., "Social Mobility: The Barro-Becker Children meet the LaitnerLoury Dynasties," Review of Economic Dynamics, 1999, 2 (1), 65-103.

Barro, Robert J. and Gary S. Becker, "Fertility Choice in a Model of Economic Growth," Econometrica, 1989, 57 (2), 481-501.

- and Jose F. Ursua, "Macroeconomic Crises since 1870," NBER Working Paper 13940, National Bureau of Economic Research 2008.

Becker, Gary S. and Robert J. Barro, "A Reformulation of the Theory of Fertility," Quarterly Journal of Economics, 1988, 103 (1), 1-25.

Brock, William A. and Leonard J. Mirman, "Optimal economic growth and uncertainty: The discounted case," Journal of Economic Theory, June 1972, 4 (3), 479-513.

Butz, William P. and Michael P. Ward, "The Emergence of Countercyclical U.S. Fertility," The American Economic Review, 1979, 69 (3), 318-328. 
Caldara, Dario, Jesús Fernández-Villaverde, Juan F. Rubio-Ramírez, and Wen Yao, "Computing DSGE models with recursive preferences and stochastic volatility," Review of Economic Dynamics, 2012, 15 (2), 188 - 206.

Caucutt, Elizabeth M., Nezih Guner, and John Knowles, "Why do Women Wait? Matching, Wage Inequality, and The Incentives for Fertility Delay," Review of Economic Dynamics, 2002, 5 (4), 815-855.

Cette, Gilbert, Yusuf Kocoglu, and Jacques Mairesse, "Productivity Growth and Levels in France, Japan, the United Kingdom and the United States in the Twentieth Century," NBER Working Paper 15577, National Bureau of Economic Research 2009.

Chari, V. V., Patrick J. Kehoe, and Ellen R. McGrattan, "Business Cycle Accounting," Econometrica, 2007, 75 (3), 781-836.

Chesnais, Jean Claude, The Demographic Transition: Stages, Patterns, and Economic Implications: A Longitudinal Study of Sixty-seven Countries Covering the Period 1720-1984, Oxford University Press, 1992.

Doepke, Matthias, Moshe Hazan, and Yishay Maoz, "The Baby Boom and World War II: A Macroeconomic Analysis," Review of Economic Studies, July 2015, 82 (3).

Easterlin, Richard A., "The American Baby Boom in Historical Perspective," The American Economic Review, 1961, 51 (5), 869-911.

_, Population, Labor Force, and Long Swings in Economic Growth, National Bureau of Economic Research, 1968.

_, "What Will 1984 Be Like? Socioeconomic Implications of Recent Twists in Age Structure," Demography, 1978, 15 (4), 397-432.

_, Birth and Fortune, 2nd ed., University of Chicago Press, Chicago, IL, 1987.

Feichtinger, Gustav and Engelbert J. Dockner, "Capital Accumulation, Endogenous Population Growth, and Easterlin Cycles," Journal of Population Economics, 1990, 3, 73-87.

- and Gerhard Sorger, "Self-Generated Fertility Waves in a Non-Linear Continuous Overlapping Generations Model," Journal of Population Economics, 1989, 2, 267-280.

Greenwood, Jeremy, Ananth Seshadri, and Guillaume Vandenbroucke, "The Baby Boom and Baby Bust," Research Report 1, Economie d'Avant Garde July 2002. 
_ , _ , and _ , "The Baby Boom and Baby Bust," The American Economic Review, 2005, 95 (1), 183-207.

Hacker, David, "The Human Cost of War: White Populationin the United States, 1850-1880." PhD dissertation, University of Minnesota 1999.

Haines, Michael R., "The Population of the United States, 1790-1920," Historical Working Paper 56, National Bureau of Economic Research 1994.

Hansen, Gary D., "The Cyclical and Secular Behaviour of the Labour Input: Comparing Efficiency Units and Hours Worked," Journal of Applied Econometrics, 1993, $8(1), 71-80$.

Huggett, Mark, "Wealth distribution in life-cycle economies," Journal of Monetary Economics, 1996, 38 (3), 469-494.

Jones, Larry E. and Alice Schoonbroodt, "Baby Busts and Baby Booms: The Fertility Response to Shocks in Dynastic Models," NBER Working Paper 16596, National Bureau of Economic Research 2010.

_ and _ , "Complements versus Substitutes and Trends in Fertility Choice in Dynastic Models," International Economic Review, 2010, 51 (3), 671-699.

- and Michèle Tertilt, "An Economic History of Fertility in the U.S.: 1826-1960," in Peter Rupert, ed., Frontiers of Family Economics, Vol. 1, Emerald Press, 2008.

Kamenik, Ondra, "DSGE Models with Dynare++. A Tutorial," Dynare Project 2011. http://www.dynare.org/documentation-and-support/dynarepp/dynare-tutorial.pdf.

Kopczuk, Wojciech and Emmanuel Saez, "Top Wealth Shares in the United States, 1916-2000: Evidence from Estate Tax Returns," National Tax Journal, June 2004, 57 (2), 445-87.

Kydland, Finn E and Edward C Prescott, "Time to Build and Aggregate Fluctuations," Econometrica, November 1982, 50 (6), 1345-70.

Lee, Ronald, "The Formal Dynamics of Controlled Populations and the Echo, the Boom and the Bust," Demography, 1974, 11 (4), 563-585.

Lee, Ronald D., "Population Dynamics," in S.N. Durlauf and L.E. Blume, eds., The New Palgrave Dictionary of Economics, Basingstoke: Palgrave Macmillan, 2008. 
Light, A. and K. McGarry, "Why Parents Play Favorites: Explanations for Unequal Bequests," The American Economic Review, 2004, 94(5), 1669-1681.

Lino, Mark, "Expenditures on Children by Families, 2001 Annual Report," Technical Report, UNITED STATES DEPARTMENT OF AGRICULTURE 2002.

Lucas, Robert E., The Industrial Revolution: Past and Future. Lectures on Economic Growth, Cambridge: Harvard University Press., 2002.

Macunovich, Diane J., "Fertility and the Easterlin Hypothesis: An Assessment of the Literature," Journal of Population Economics, 1998, 11, 53-111.

_ and Richard A. Easterlin, "Easterlin Hypothesis," in S.N. Durlauf and L.E. Blume, eds., The New Palgrave Dictionary of Economics, Basingstoke: Palgrave Macmillan, 2008.

Manuelli, Rodolfo E. and Ananth Seshadri, "Explaining International Fertility Differences," Quarterly Journal of Economics, 2009, 124 (2), 771-807.

Mateos-Planas, Xavier, "The Demographic Transition in Europe: A Neoclassical Dynastic Approach," Review of Economic Dynamics, July 2002, 5 (3), 646-680.

Mitchell, Brian R., International Historical Statistics: Europe, 1750-1993, New York, N.Y.: Stockton Press, 1998.

Piketty, Thomas and Emmanuel Saez, "Income Inequality in the United States, 1913-1998," NBER Working Papers 8467, National Bureau of Economic Research, Inc September 2001.

_ and _ , "Income Inequality In The United States, 1913-1998," The Quarterly Journal of Economics, February 2003, 118 (1), 1-39.

Samuelson, Paul A., "An Economist's Non-Linear Model of Self-Generated Fertility Waves," Population Studies, 1976, 30 (2), 243-247.

Scholz, John Karl and Ananth Seshadri, "Children and Household Wealth," Working Paper, University of Wisconsin 2009.

Schoonbroodt, Alice, "Baby Busts and Baby Booms, The Fertility Response to Economic Shocks." PhD dissertation, University of Minnesota 2006. 
_ , "Parental Child Care During and Outside of Typical Work Hours," Review of Economics of the Household, 2016, forthcoming.

_ and Michèle Tertilt, "Property Rights and Efficiency in OLG Models with Endogenous Fertility," Journal of Economic Theory, March 2014, 150, 551-582.

Sobotka, Tomas, Vegard Skirbekk, and Dimiter Philipov, "Economic Recession and Fertility in the Developed World. A Literature Review," Population and Development Review, 2011, 37 (2), 267-306.

Sommer, Kamila, "Fertility Choice in a Life Cycle Model with Idiosyncratic Uninsurable Earnings Risk," Working Paper, Georgetown University 2010.

Statistisches Bundesamt, Wiesbaden, "Zusammenfassende Übersichten, 1 Eheschliessungen, Geborene und Gestorbene, 1.4 Deutschland, Verhältniszahlen," 2007.

Vandenbroucke, Guillaume, "Fertility and Wars: The Case of World War I in France," American Economic Journal: Macroeconomics, April 2014, 6 (2), 108-136. 